\title{
Role of Side-Chain Architecture in Poly(ethylene oxide)-based copolymers
}

Zhishuai Geng, ${ }^{\dagger}$ Nicole S. Schauser, ${ }^{\dagger, \#}$ Jongbok Lee, ${ }^{\dagger, \Delta}$ Rayco Perez Schmeller, ${ }^{\dagger}$ Stephanie M. Barbon, ${ }^{\dagger}$ Rachel A. Segalman, ${ }^{,, \#, ~ N a t h a n i e l ~ A . ~ L y n d, ~}{ }^{*, \neq}$ Craig J. Hawker, ${ }^{*,+\#}$

†Materials Research Laboratory, University of California Santa Barbara, Santa Barbara, California 93106, United States. \#Materials Department, University of California Santa Barbara, Santa Barbara, California 93106, United States. §Department of Chemical Engineering, University of California Santa Barbara, Santa Barbara, California 93106, United States.

${ }^{\ddagger}$ McKetta Department of Chemical Engineering, The University of Texas at Austin, Austin, TX, 78712, United States.

${ }^{\Delta}$ Department of Biological and Chemical Engineering, Hongik University, 2639, Sejong-ro, Jochiwon-eup, Sejongsi, 30016, Republic of Korea.

\section{Table of Contents}

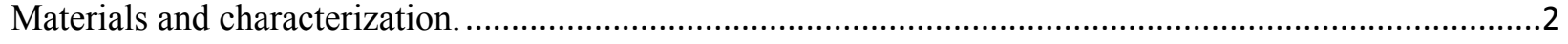

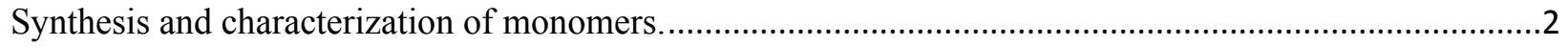

Synthesis and characterization of PEO-based copolymers. ...................................................................

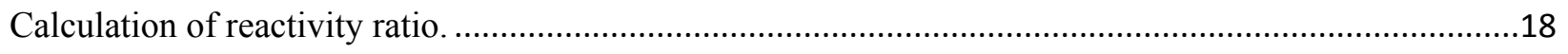

Comprehensive thermal characterization of copolymers.................................................................20

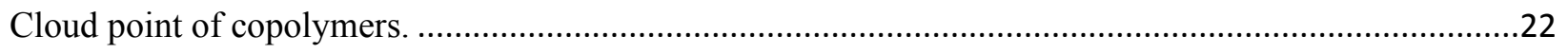

PEO-based copolymers with dispersed PEG side chain. ................................................................23

Conductivity characterization of PEO-based copolymers. ..................................................................24 


\section{Materials and characterization.}

All chemicals were used as received from Sigma-Aldrich, Alfa Aesar, and TCI unless otherwise specified. THF was collected from a dry solvent system and used immediately thereafter. Ethylene oxide (EO) was degassed through freeze-pump-thaw cycle and distilled to a flame-dried buret immediately before use. Potassium naphthalenide was prepared from potassium metal and recrystallized naphthalene in dry THF and allowed to stir with a glass-coated stir-bar for $24 \mathrm{~h}$ at room temperature before use.

${ }^{1} \mathrm{H}$ NMR spectroscopy was carried out on a Varian Unity Inova $600 \mathrm{MHz}$, Varian Unity Inova $500 \mathrm{MHz}$ and Bruker AVANCE III Ultrashield Plus $800 \mathrm{MHz}$ spectrometer in deuterated chloroform $\left(\mathrm{CDCl}_{3}\right)$. Size exclusion chromatography (SEC) or gel permeation chromatography (GPC) was performed on a Waters chromatograph with four Viscotek columns (two I-MBHMW-3078, I-series mixed bed high molecular weight columns and two IMBLMW-3078, I-series mixed bed low molecular weight columns) for fractionation, a Waters 2414 differential refractometer, and a 2996 photodiode array detector for detection of eluent, and chloroform with $0.1 \%$ triethlyamine at room temperature was used as the mobile phase. DSC measurements were performed using a TA Instruments Q2000 MDSC (modulated differential scanning calorimeter) with 50-position autosampler and mass flow control in the temperature range from -80 to 120

${ }^{\circ} \mathrm{C}$ at heating rates of $10 \mathrm{~K} / \mathrm{min}$ and cooling rates of $-5 \mathrm{~K} / \mathrm{min}$ under nitrogen. Cloud point was measured on a Shimadzu UV3600 UV-Nir-NIR Spectrometer at various temperature.

\section{Synthesis and characterization of monomers.}

(Glycidyloxy)methyl-12-crown-4 (C4): To KH $(0.20 \mathrm{~g}, 1.5 \mathrm{mmol}, 30 \mathrm{wt} \%$ in mineral oil) in $8 \mathrm{~mL}$ of dry THF was added 2-(hydroxymethyl)-12-crwon-4 $(0.21 \mathrm{~g}, 1.0 \mathrm{mmol})$ in $8 \mathrm{~mL}$ of dry THF over $1 \mathrm{~h}$ at room temperature under nitrogen atmosphere. The mixture was stirred at room temperature for $1 \mathrm{~h}$. To the mixture was added epichlorohydrin $(0.20 \mathrm{~mL}, 2.5 \mathrm{mmol})$ in $10 \mathrm{~mL}$ of dry THF over $30 \mathrm{~min}$ at room temperature under nitrogen atmosphere. The reaction was stirred at room temperature for $24 \mathrm{~h}$. The reaction was cooled down to $0{ }^{\circ} \mathrm{C}$ and slowly quenched with water and neutralized with $0.1 \mathrm{M} \mathrm{HCl}$ (the color of the mixture turned from brown to yellow). THF was removed under reduced pressure, and the crude product was dissolved in $20 \mathrm{~mL}$ of DCM and extracted with water ( $3 \mathrm{X} 10 \mathrm{~mL})$. The organic layer was dried over $\mathrm{Na}_{2} \mathrm{SO}_{4}$ and concentrated in vacuo. The crude product was filtered through short pad of neutral alumina using DCM, followed by removal of DCM under reduced pressure and purified by column chromatography using a gradient eluent, DCM:IPA (98:2) to DCM:IPA (95:5) affording C4 (0.13 $\mathrm{g}, 48 \%)$ as colorless oil. ${ }^{1} \mathrm{H}$ NMR $(600 \mathrm{MHz}$, Chloroform-d) $\delta 3.84(\mathrm{~m}, 1 \mathrm{H}), 3.81-3.61(\mathrm{~m}, 14 \mathrm{H}), 3.60-$ $3.48(\mathrm{~m}, 3 \mathrm{H}), 3.41(\mathrm{dt}, \mathrm{J}=11.6,5.8 \mathrm{~Hz}, 1 \mathrm{H}), 3.18-3.10(\mathrm{~m}, 1 \mathrm{H}), 2.79(\mathrm{dd}, \mathrm{J}=5.0,4.2 \mathrm{~Hz}, 1 \mathrm{H}), 2.60$ (ddd, J = 6.2, 5.0, $2.7 \mathrm{~Hz}, 1 \mathrm{H}) .{ }^{13} \mathrm{C}$ NMR (125 MHz, Chloroform-d) $\delta$ 78.7, 72.2, 71.7, 71.1, 70.84, 70.79, 70.5, 70.3, 50.9, 44.2. 


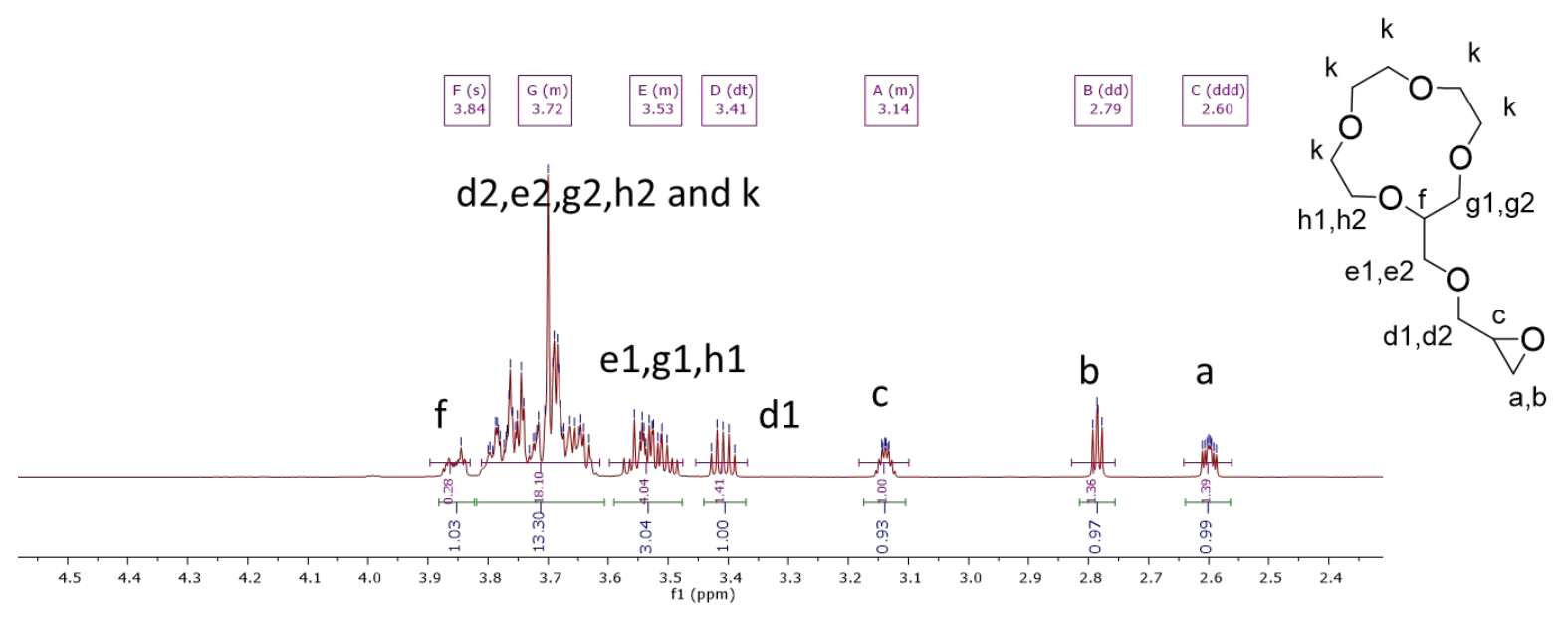

Figure S1. ${ }^{1} \mathrm{H}$ NMR of monomer $\mathbf{C 4}$.

(Glycidyloxy)methyl-15-crown-5 (C5): To $\mathrm{NaH}(0.12 \mathrm{~g}, 3.0 \mathrm{mmol}, 60 \%$ in mineral oil) in $10 \mathrm{~mL}$ of dry THF was added 2-(hydroxymethyl)-15-crwon-5 (0.51 g, $2.0 \mathrm{mmol})$ in $10 \mathrm{~mL}$ of dry THF over $1 \mathrm{~h}$ at room temperature under nitrogen atmosphere. The mixture was stirred at room temperature for $1 \mathrm{~h}$. To the mixture was added epichlorohydrin $(0.40 \mathrm{~mL}, 5.0 \mathrm{mmol})$ in $15 \mathrm{~mL}$ of dry THF over $30 \mathrm{~min}$ at room temperature under nitrogen atmosphere. The reaction was stirred at room temperature for $24 \mathrm{~h}$. The reaction was cooled down to $0^{\circ} \mathrm{C}$ and slowly quenched with water and neutralized with $0.1 \mathrm{M} \mathrm{HCl}$ (the color of the mixture turned from brown to yellow). THF was removed under reduced pressure, and the crude product was dissolved in $30 \mathrm{~mL}$ of DCM and extracted with water ( 3 X $15 \mathrm{~mL}$ ). The organic layer was dried over $\mathrm{Na}_{2} \mathrm{SO}_{4}$ and concentrated in vacuo. The crude product was filtered through short pad of neutral alumina using DCM, followed by removal of DCM under reduced pressure and purified by column chromatography using a gradient eluent, DCM:IPA (96:4) to DCM:IPA (92:8) affording C5 (0.46 g, $76 \%$ ) as colorless oil. ${ }^{1} \mathrm{H}$ NMR $(600 \mathrm{MHz}$, Chloroform-d) $\delta 3.84$ (ddt, J = 11.5, 4.5, $3.6 \mathrm{~Hz}, 1 \mathrm{H}), 3.81$ $-3.51(\mathrm{~m}, 21 \mathrm{H}), 3.43(\mathrm{ddd}, \mathrm{J}=11.6,9.5,5.8 \mathrm{~Hz}, 1 \mathrm{H}), 3.14(\mathrm{ddq}, \mathrm{J}=5.7,4.1,2.8 \mathrm{~Hz}, 1 \mathrm{H}), 2.78(\mathrm{dd}, \mathrm{J}=$ 5.0, 4.1 Hz, 1H), 2.60 (ddd, J = 6.6, 5.0, $2.7 \mathrm{~Hz}, 1 \mathrm{H}) .{ }^{13} \mathrm{C}$ NMR $(125 \mathrm{MHz}$, Chloroform-d) $\delta$ 78.6, 72.0, 71.7, 71.2, 71.0, 70.8, 70.7, 70.50, 70.46, 70.2, 50.8, 44.1.

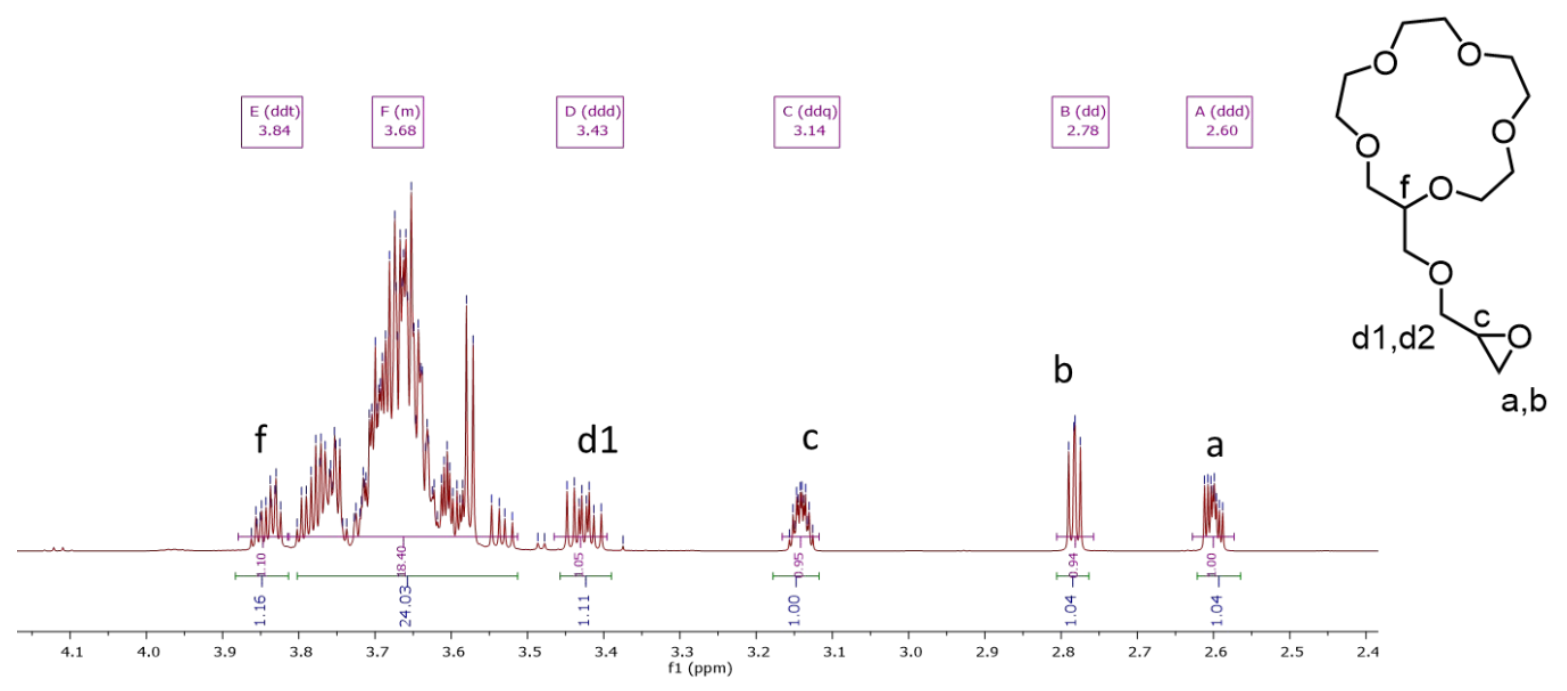

Figure S 2. ${ }^{1} \mathrm{H}$ NMR of monomer C5. 
(Glycidyloxy)methyl-18-crown-6 (C6): To $\mathrm{NaH}(0.48 \mathrm{~g}, 12.0 \mathrm{mmol}, 60 \%$ in mineral oil) in $35 \mathrm{~mL}$ of dry THF was added 2-(hydroxymethyl)-18-crwon-6 $(2.0 \mathrm{~g}, 8.0 \mathrm{mmol})$ in $35 \mathrm{~mL}$ of dry THF over $1 \mathrm{~h}$ at room temperature under nitrogen atmosphere. The mixture was stirred at room temperature for $1 \mathrm{~h}$. To the mixture was added epichlorohydrin $(1.57 \mathrm{~mL}, 20.0 \mathrm{mmol})$ in $50 \mathrm{~mL}$ of dry THF over $30 \mathrm{~min}$ at room temperature under nitrogen atmosphere. The reaction was stirred at room temperature for $24 \mathrm{~h}$. The reaction was cooled down to $0{ }^{\circ} \mathrm{C}$ and slowly quenched with water and neutralized with $0.1 \mathrm{M} \mathrm{HCl}$ (the color of the mixture turned from brown to yellow). THF was removed under reduced pressure, and the crude product was dissolved in $60 \mathrm{~mL}$ of DCM and extracted with water ( 3 X $30 \mathrm{~mL}$ ). The organic layer was dried over $\mathrm{Na}_{2} \mathrm{SO}_{4}$ and concentrated in vacuo. The crude product was filtered through short pad of neutral alumina using DCM, followed by removal of DCM under reduced pressure and purified by column chromatography using a gradient eluent, DCM:IPA (94:6) to DCM:IPA (88:12) affording C6 $(1.59 \mathrm{~g}, 65 \%)$ as colorless oil.: $1 \mathrm{H}$ NMR $(600 \mathrm{MHz}$, Chloroform-d) $\delta 3.81(\mathrm{td}, \mathrm{J}=4.7,3.0 \mathrm{~Hz}, 2 \mathrm{H}), 3.75$ $(\mathrm{dt}, \mathrm{J}=10.4,3.4 \mathrm{~Hz}, 2 \mathrm{H}), 3.72-3.53(\mathrm{~m}, 22 \mathrm{H}), 3.42(\mathrm{ddd}, \mathrm{J}=11.7,5.8,2.6 \mathrm{~Hz}, 1 \mathrm{H}), 3.13$ (ddd, $\mathrm{J}=4.2$, 2.8, $1.2 \mathrm{~Hz}, 1 \mathrm{H}), 2.78(\mathrm{dd}, \mathrm{J}=5.1,4.1 \mathrm{~Hz}, 1 \mathrm{H}), 2.59$ (ddd, J = 5.0, 4.2, $2.7 \mathrm{~Hz}, 1 \mathrm{H}) .{ }^{13} \mathrm{C}$ NMR $(125 \mathrm{MHz}$, Chloroform-d) $\delta 78.1,71.9,71.33,71.28,70.7,70.61,70.59,70.50,70.48,70.4,69.7,50.5,43.9$.
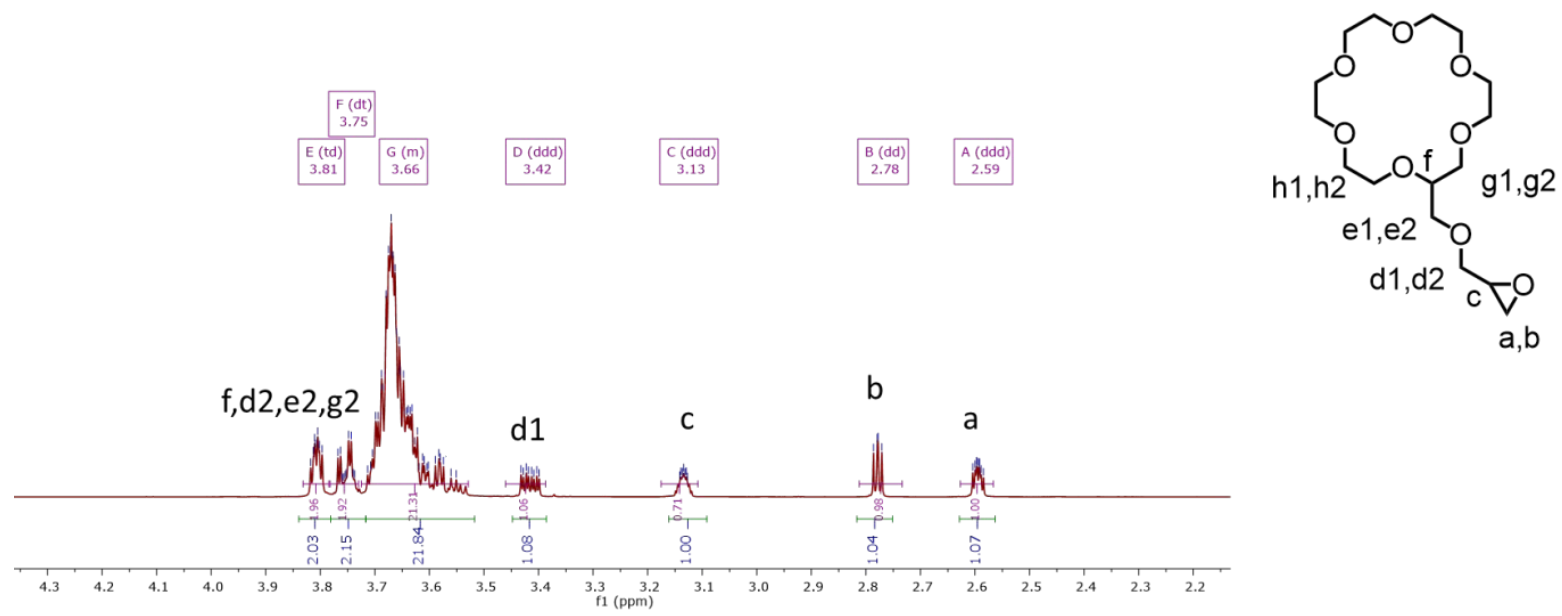

Figure S 3. ${ }^{1} \mathrm{H}$ NMR of monomer C6.

\section{Synthesis and characterization of PEO-based copolymers.}

All polymerizations were carried out on a Schlenk line in custom thick-walled glass reactors fitted with ACE threads under an inert argon atmosphere. The reactors were fitted with a buret containing a premeasured quantity of THF, a flexible connector to a buret containing ethylene oxide on ice at $0{ }^{\circ} \mathrm{C}$, a glass arm containing a port for a $6 \mathrm{~mm}$ puresep septum, and connectors to the Schlenk line. The reactors were flame-dried under vacuum and refilled with argon three times. Under a positive argon pressure atmosphere, THF drawn from a solvent purification system was introduced by opening the threaded stopcock on the attached buret. Benzyl alcohol initiator was added by gastight syringe through a $6 \mathrm{~mm}$ puresep septum. Potassium naphthalenide ( $0.3 \mathrm{M}$ in THF) was added dropwise by cannula until a light green color persisted in solution, indicating complete deprotonation of the benzyl alcohol initiator. Ethylene oxide was added by lifting the cold buret and allowing the ethylene oxide to drain into THF solution while the cryo-dried other monomer in THF solution was simultaneously added via gastight syringe. After 16 hours, reaction solution turned yellow and viscous and was quenched with $50 \mathrm{wt} \%(6 \mathrm{M})$ hydrochloric acid 
methanol solution for 2 hours and subsequently precipitated in hexane. The polymer for cloud point and conductivity study was further dissolved and dialyzed in DI water for 24 hours. Purified polymers were dried under vacuum for characterization of NMR and GPC. All the ${ }^{1} \mathrm{H}$ NMR of copolymers was taken in $\mathrm{CDCl}_{3}$, with an inset displaying details of benzyl singlet end-group dyad signals.

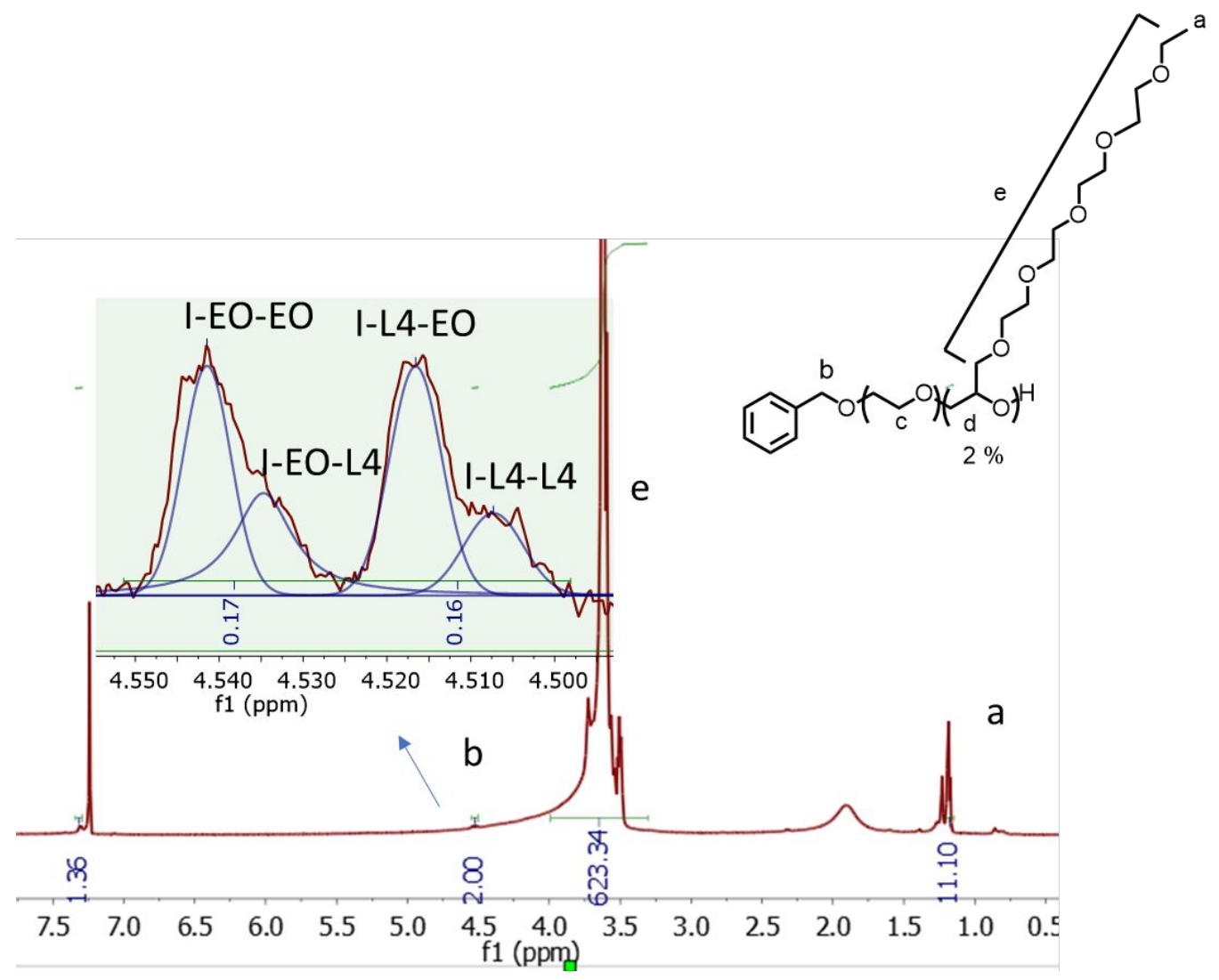

Figure S 4. ${ }^{1} \mathrm{H}$ NMR of $2 \% \mathrm{P}(\mathrm{EO}-\mathrm{L} 4)$. 


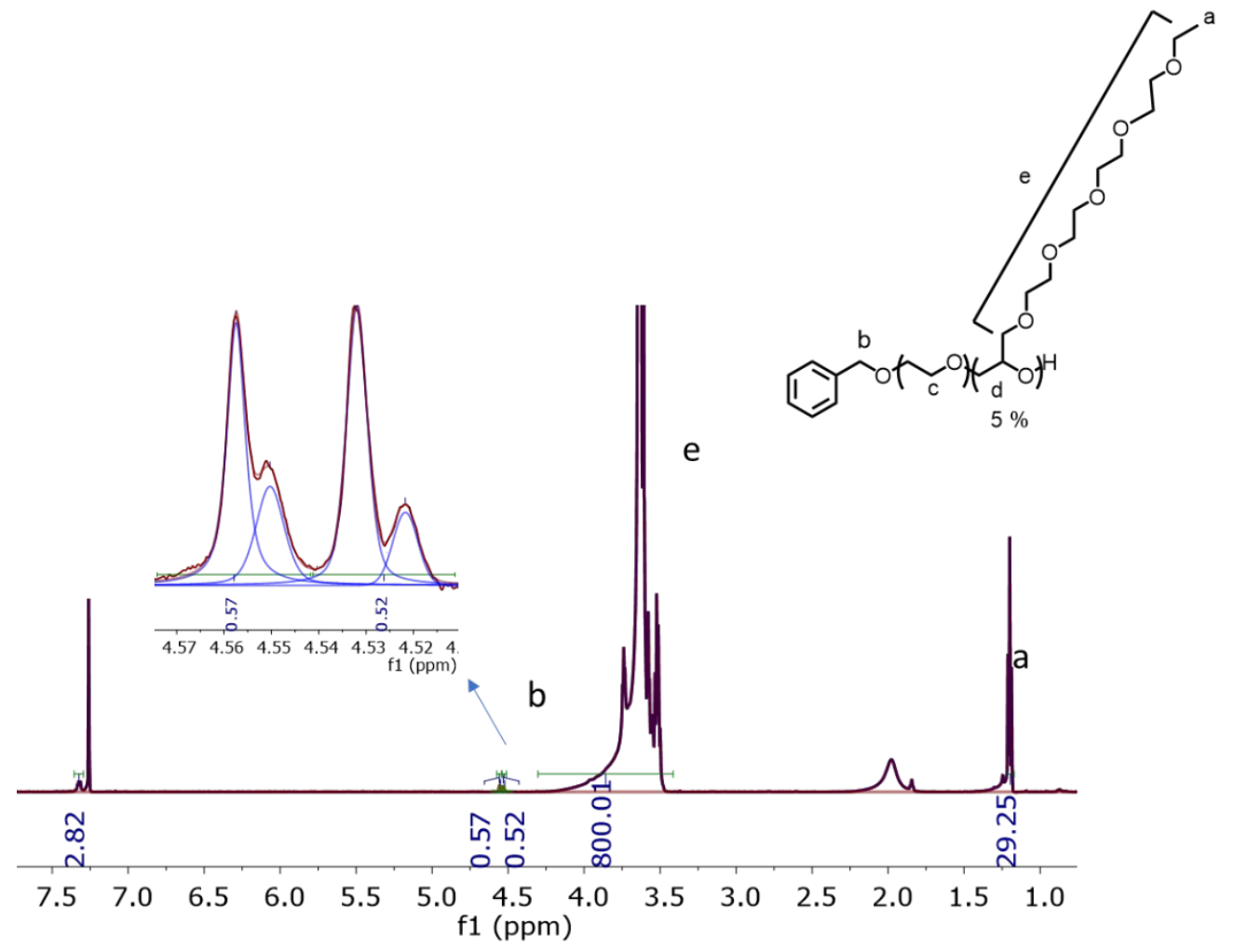

Figure S 5. ${ }^{1} \mathrm{H}$ NMR of $5 \% \mathrm{P}(\mathrm{EO}-\mathrm{L} 4)$. 


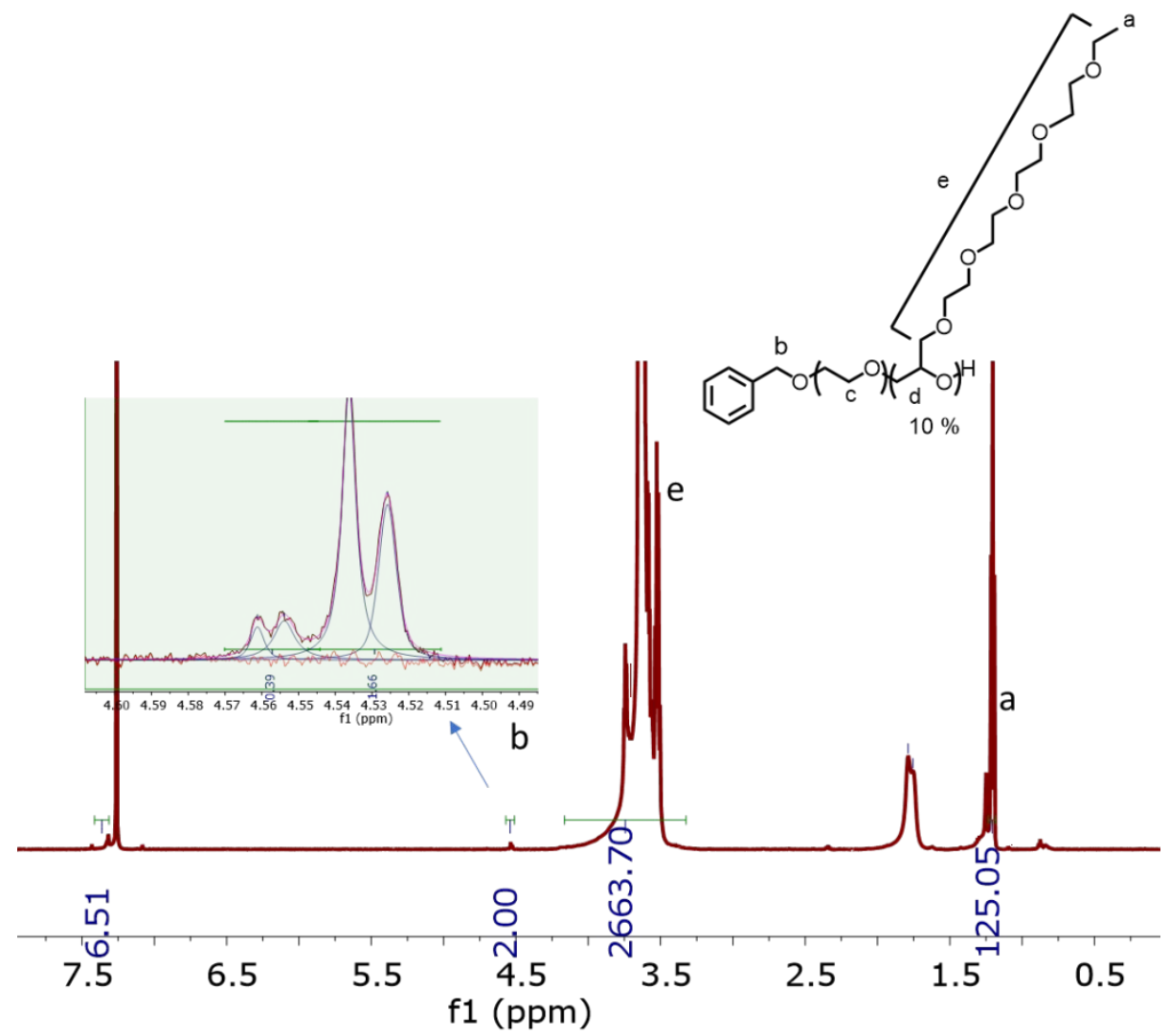

Figure S 6. ${ }^{1} \mathrm{H}$ NMR of $10 \% \mathrm{P}(\mathrm{EO}-\mathrm{L} 4)$. 


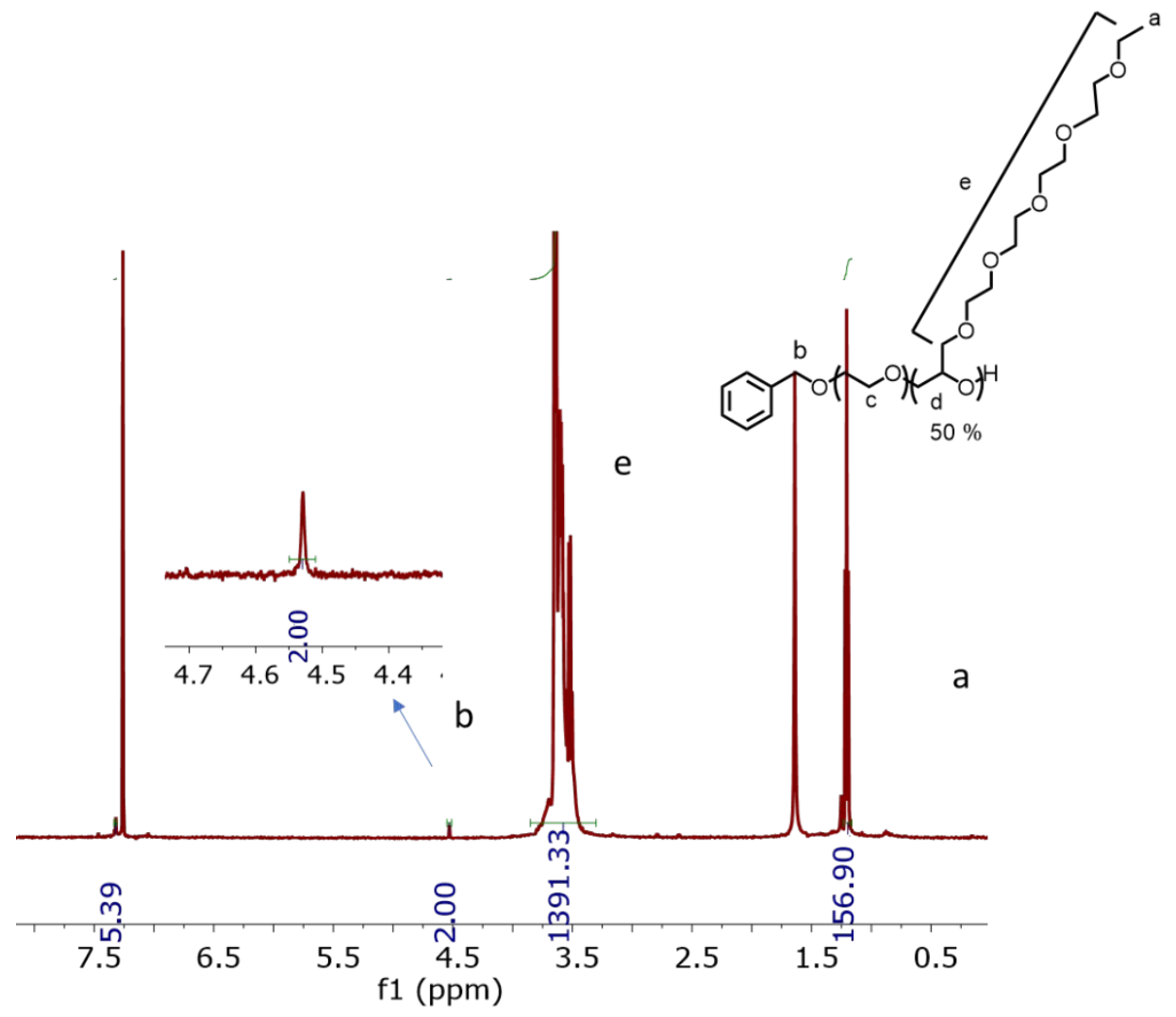

Figure S 7. ${ }^{1} \mathrm{H}$ NMR of $50 \% \mathrm{P}(\mathrm{EO}-\mathrm{L} 4)$.

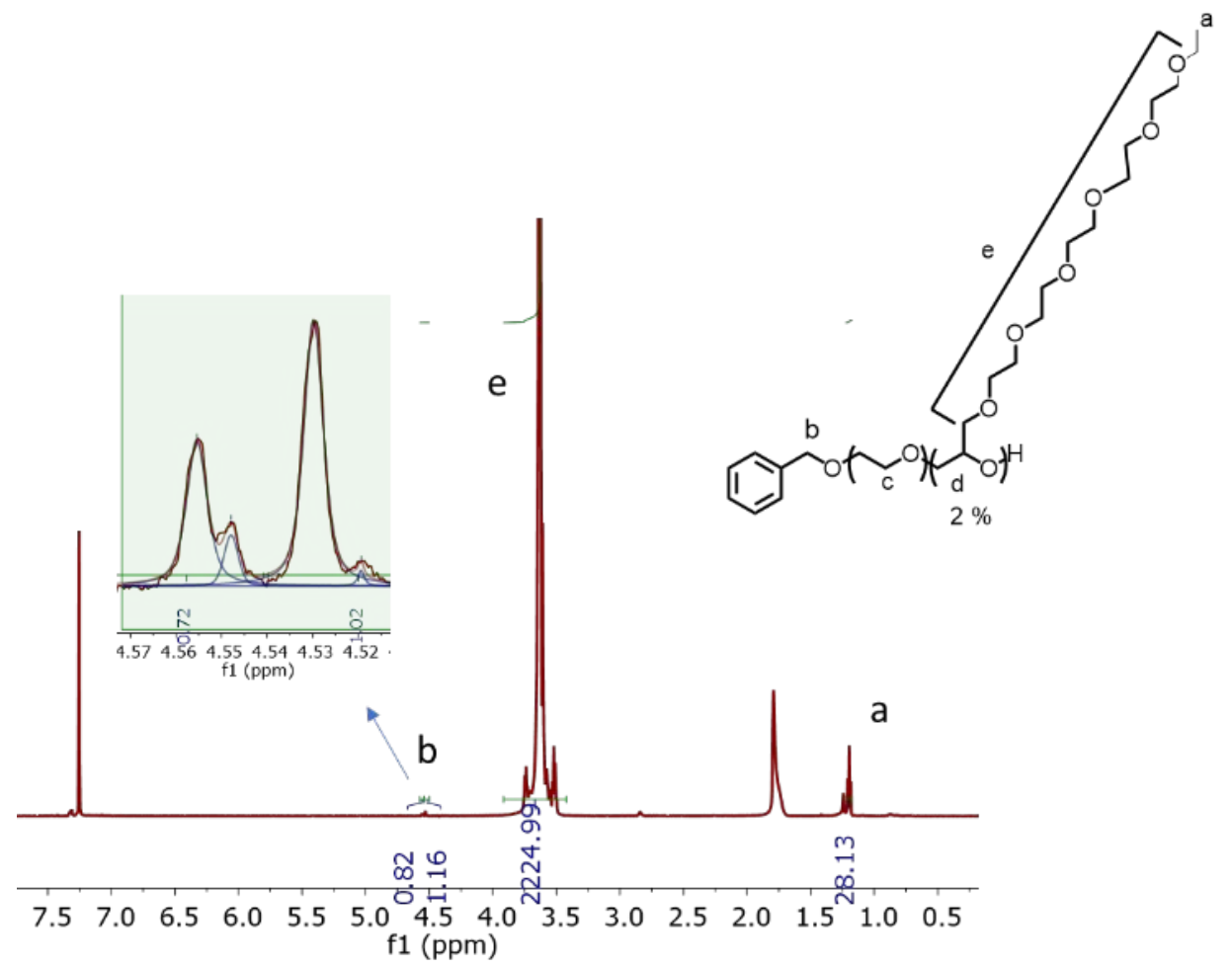

Figure S $8 .{ }^{1} \mathrm{H}$ NMR of $2 \% \mathrm{P}(\mathrm{EO}-\mathrm{L} 5)$. 


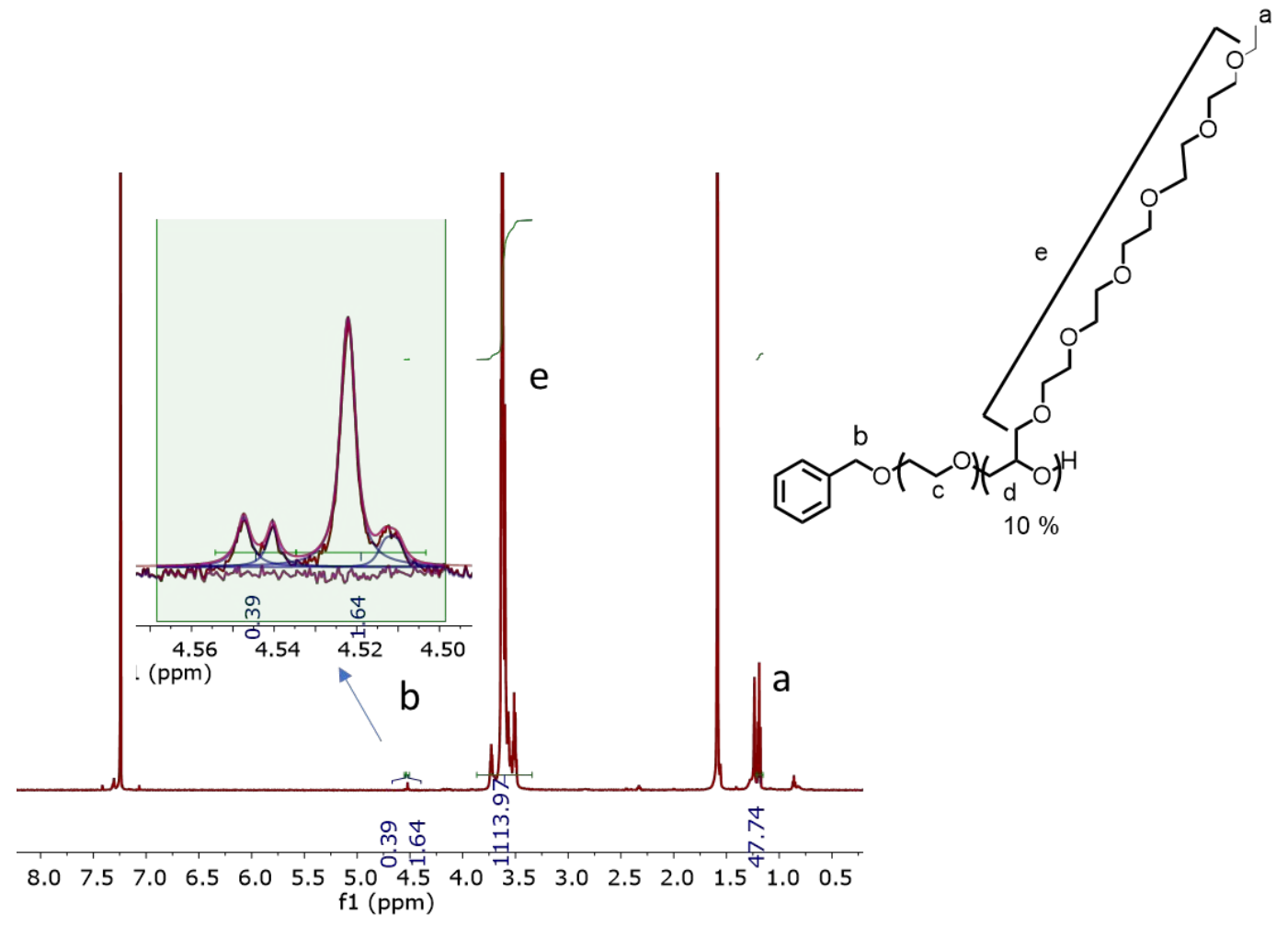

Figure S 9. ${ }^{1} \mathrm{H}$ NMR of $10 \% \mathrm{P}(\mathrm{EO}-\mathrm{L} 5)$.

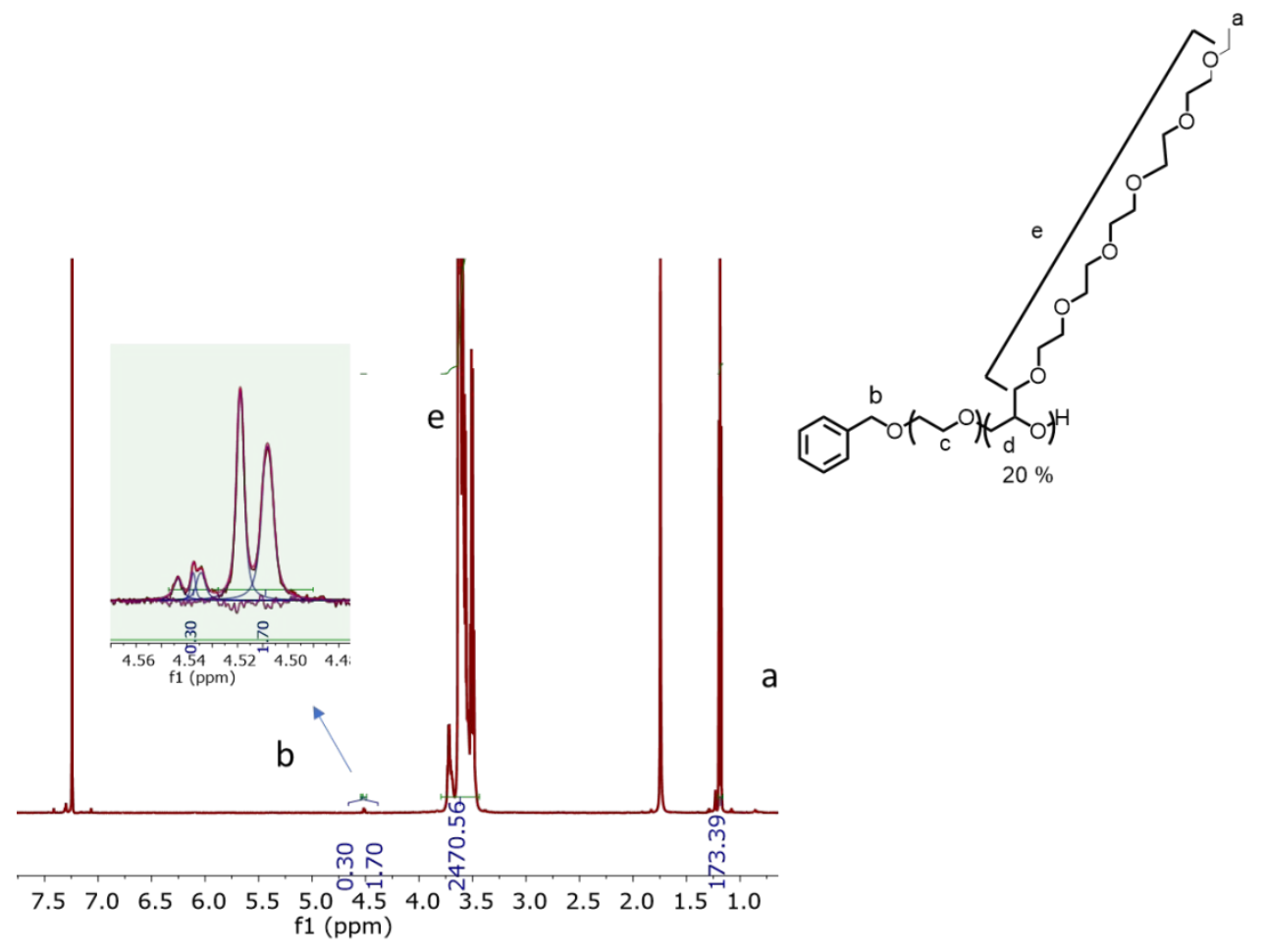

Figure S 10. ${ }^{1} \mathrm{H}$ NMR of $20 \% \mathrm{P}(\mathrm{EO}-\mathrm{L} 5)$. 


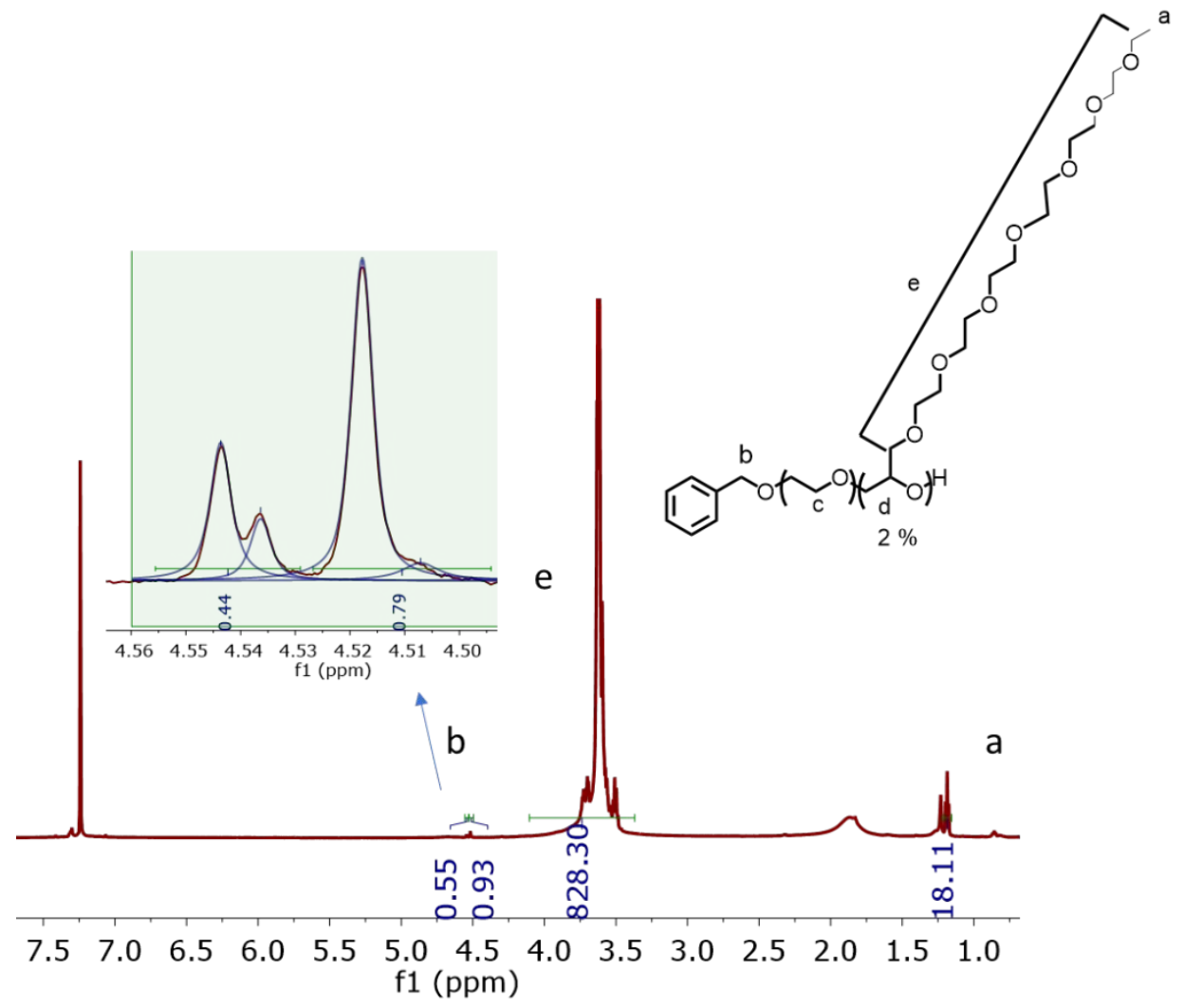

Figure S 11. ${ }^{1} \mathrm{H}$ NMR of 2\% P(EO-L6). 


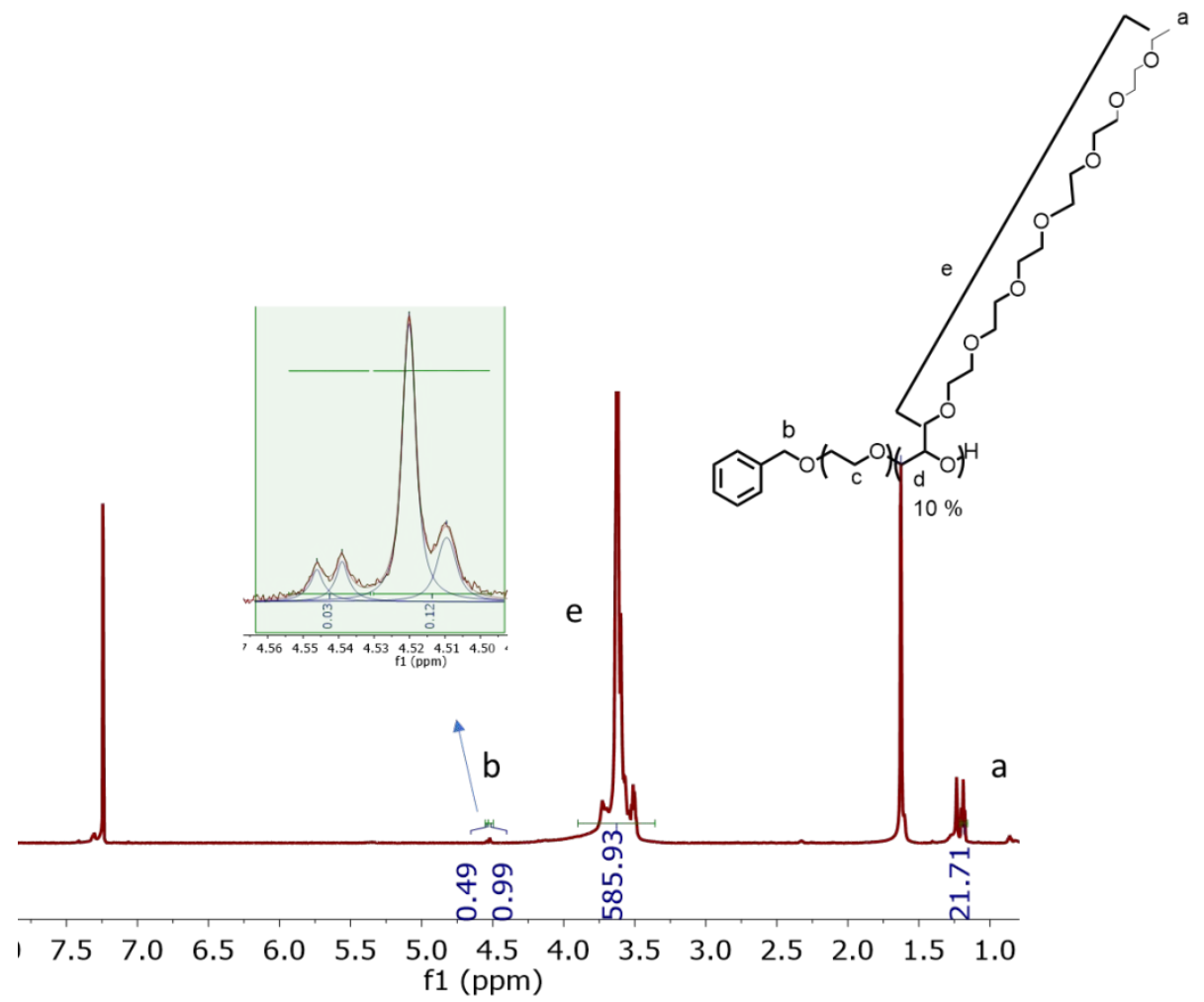

Figure S $12 .{ }^{1} \mathrm{H}$ NMR of $10 \% \mathrm{P}(\mathrm{EO}-\mathrm{L} 6)$.

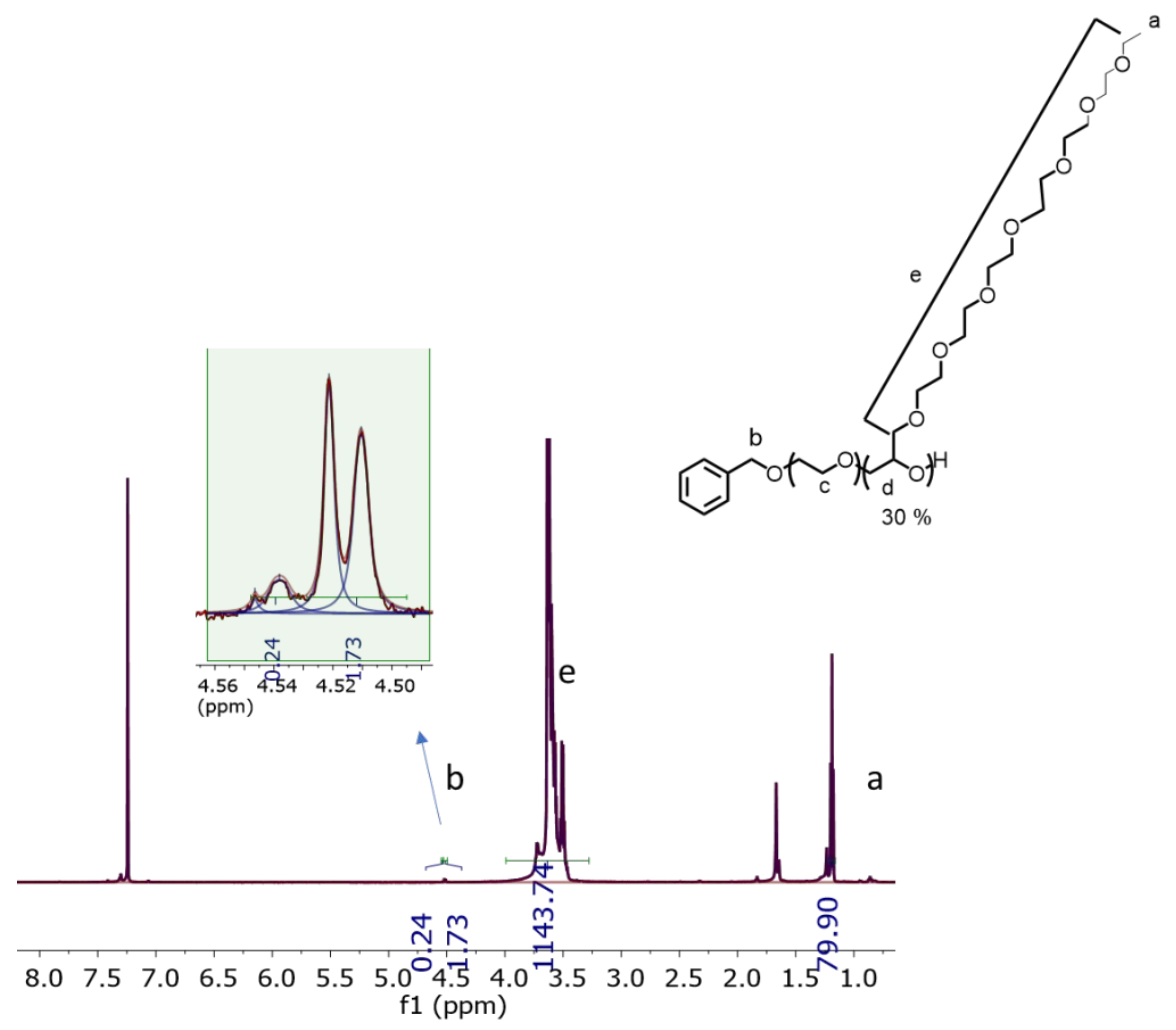

Figure S $13 .{ }^{1} \mathrm{H}$ NMR of $30 \% \mathrm{P}(\mathrm{EO}-\mathrm{L} 6)$. 


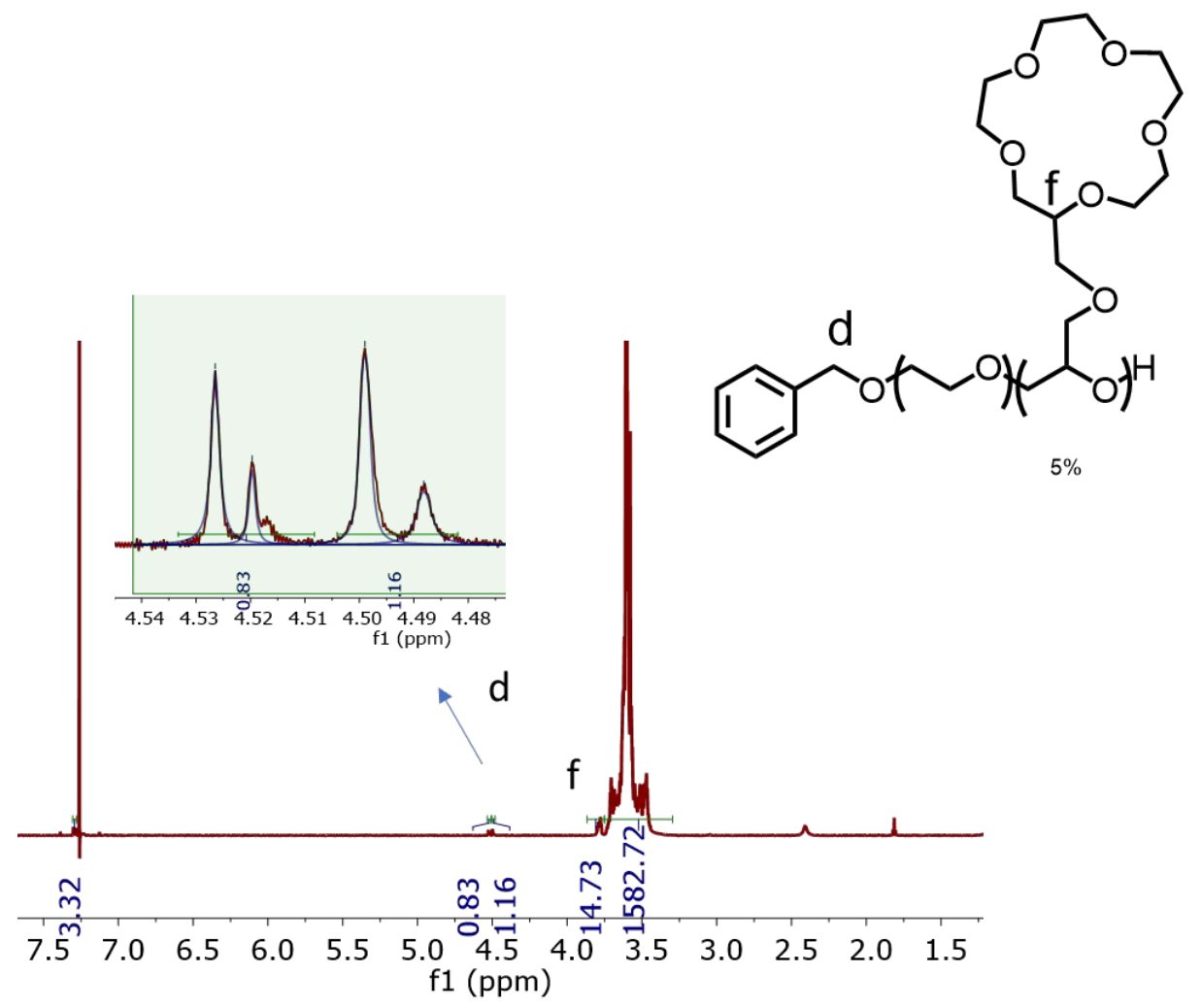

Figure S $14 .{ }^{1} \mathrm{H}$ NMR of $5 \% \mathrm{P}(\mathrm{EO}-\mathrm{C} 5)$.

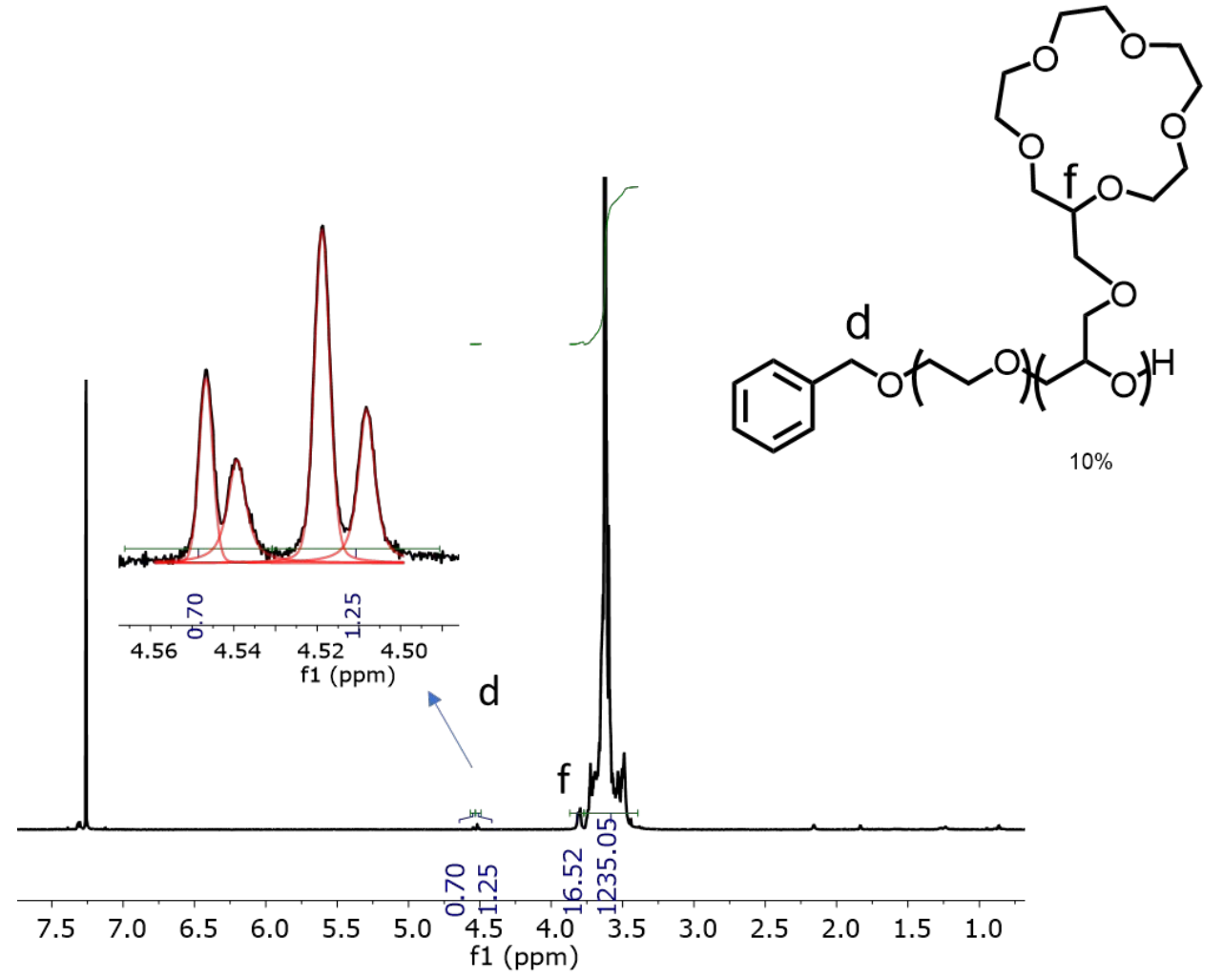

Figure S $15 .{ }^{1} \mathrm{H}$ NMR of $10 \% \mathrm{P}(\mathrm{EO}-\mathrm{C} 5)$. 


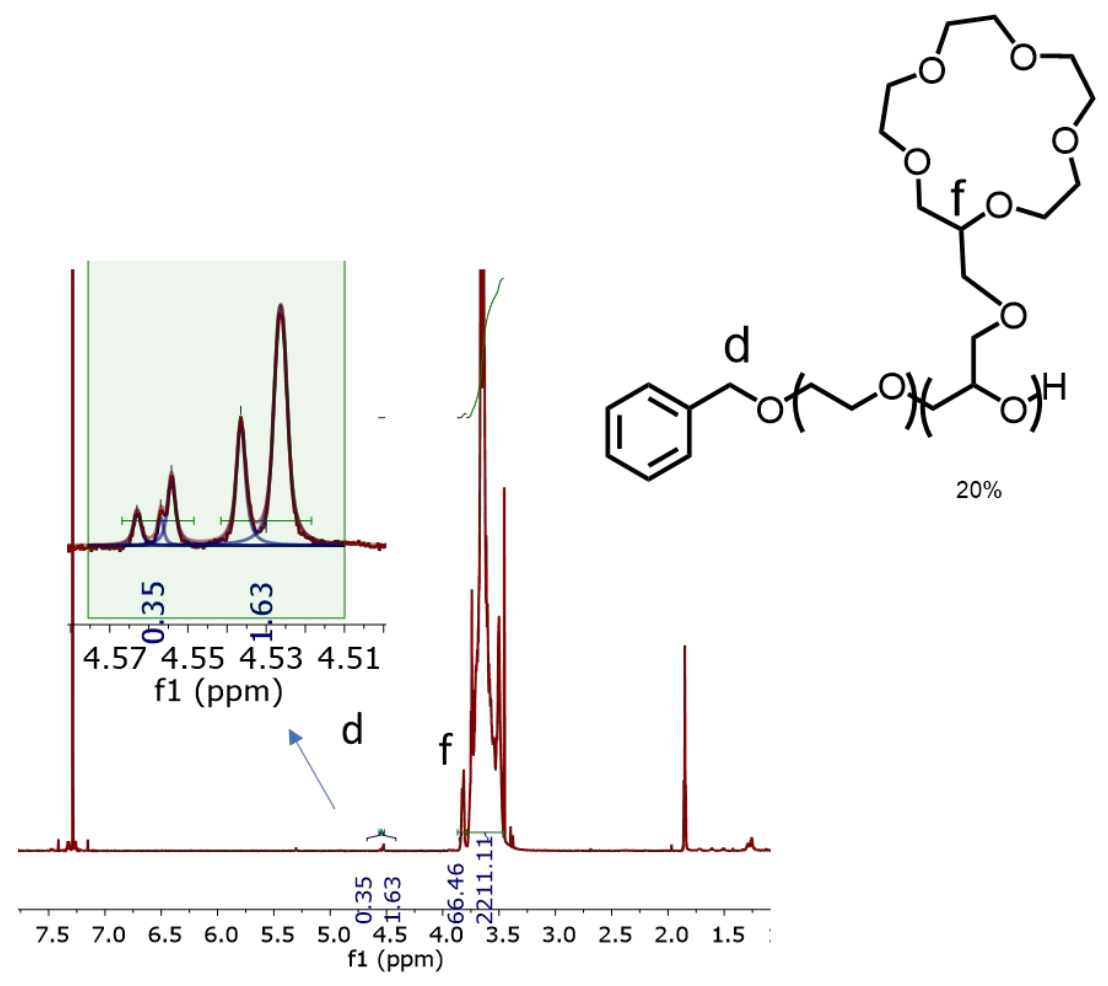

Figure S 16. ${ }^{1} \mathrm{H}$ NMR of $20 \% \mathrm{P}(\mathrm{EO}-\mathrm{C} 5)$.
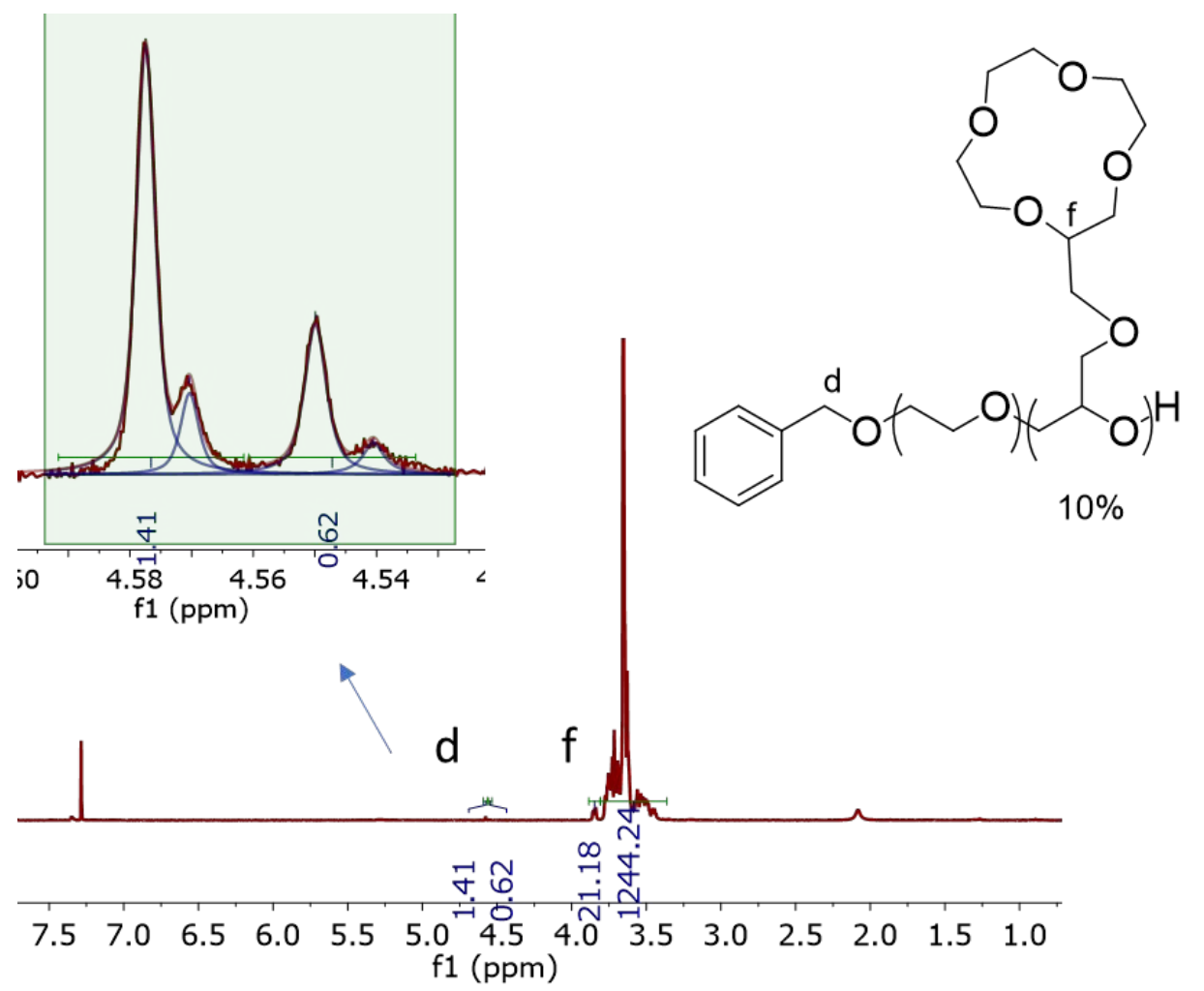

Figure S 17. ${ }^{1} \mathrm{H}$ NMR of $10 \% \mathrm{P}(\mathrm{EO}-\mathrm{C} 4)$. 


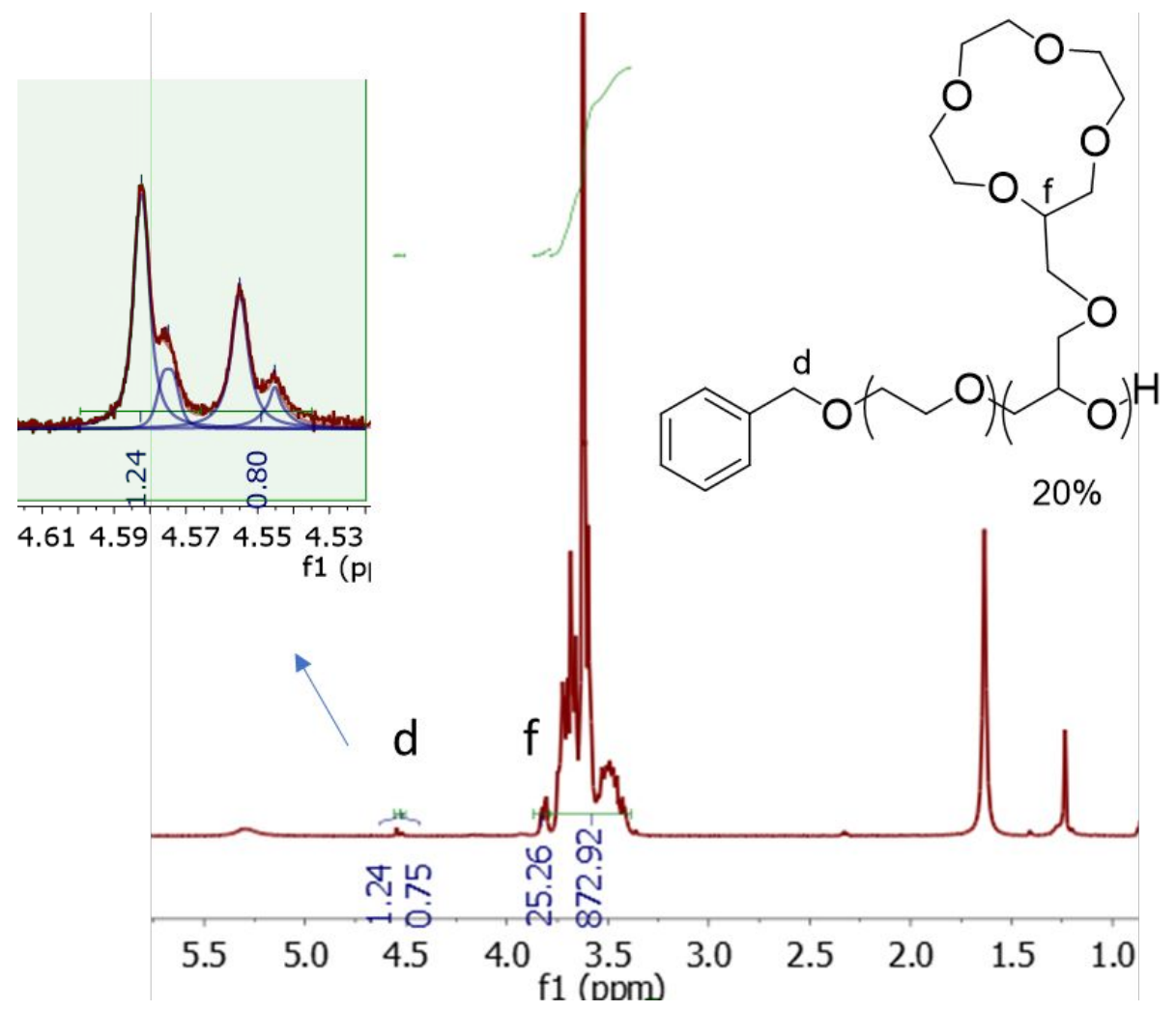

Figure S $18 .{ }^{1} \mathrm{H}$ NMR of $20 \% \mathrm{P}(\mathrm{EO}-\mathrm{C} 4)$.

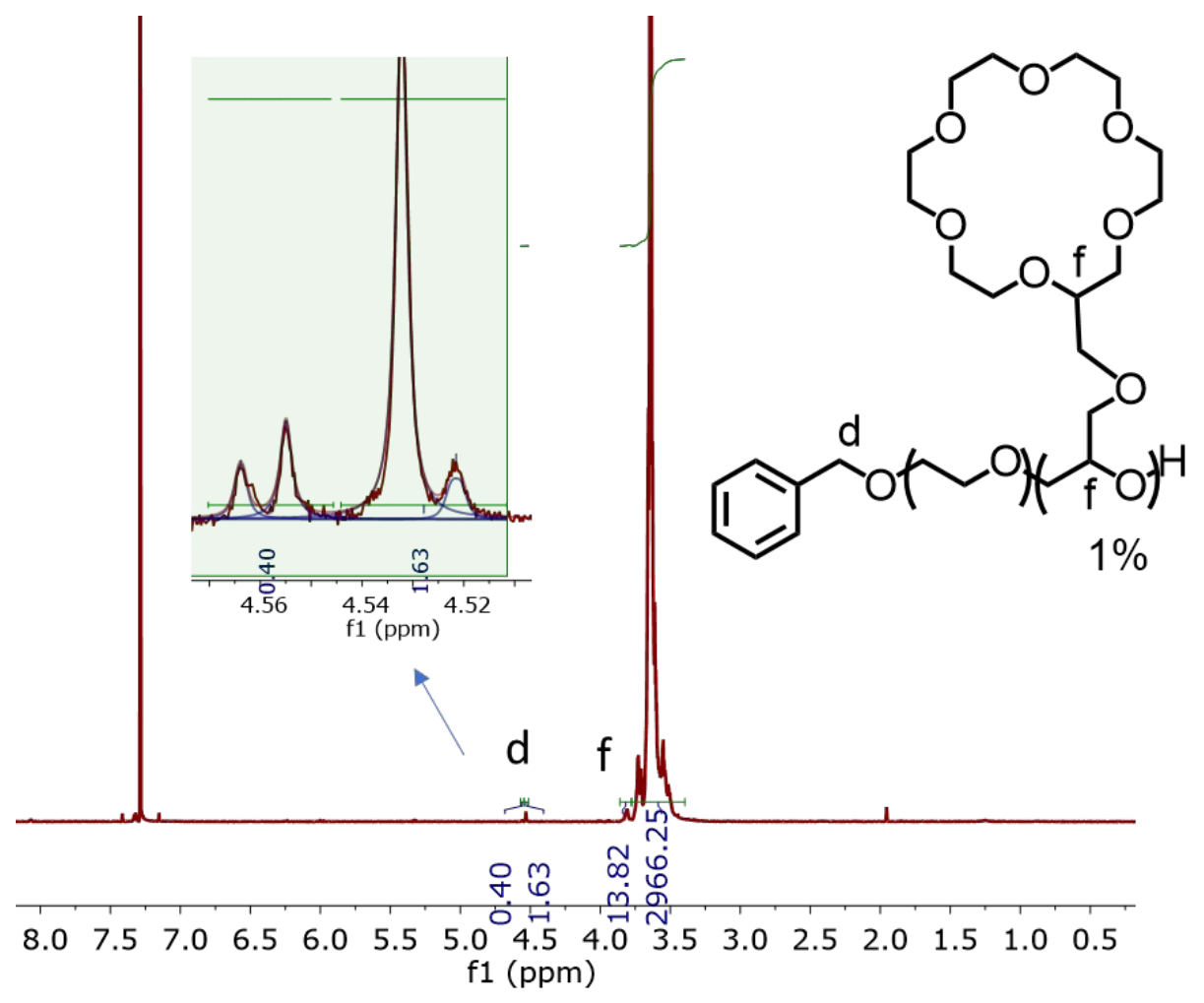

Figure S 19. ${ }^{1} \mathrm{H}$ NMR of $1 \% \mathrm{P}(\mathrm{EO}-\mathrm{C} 6)$. 


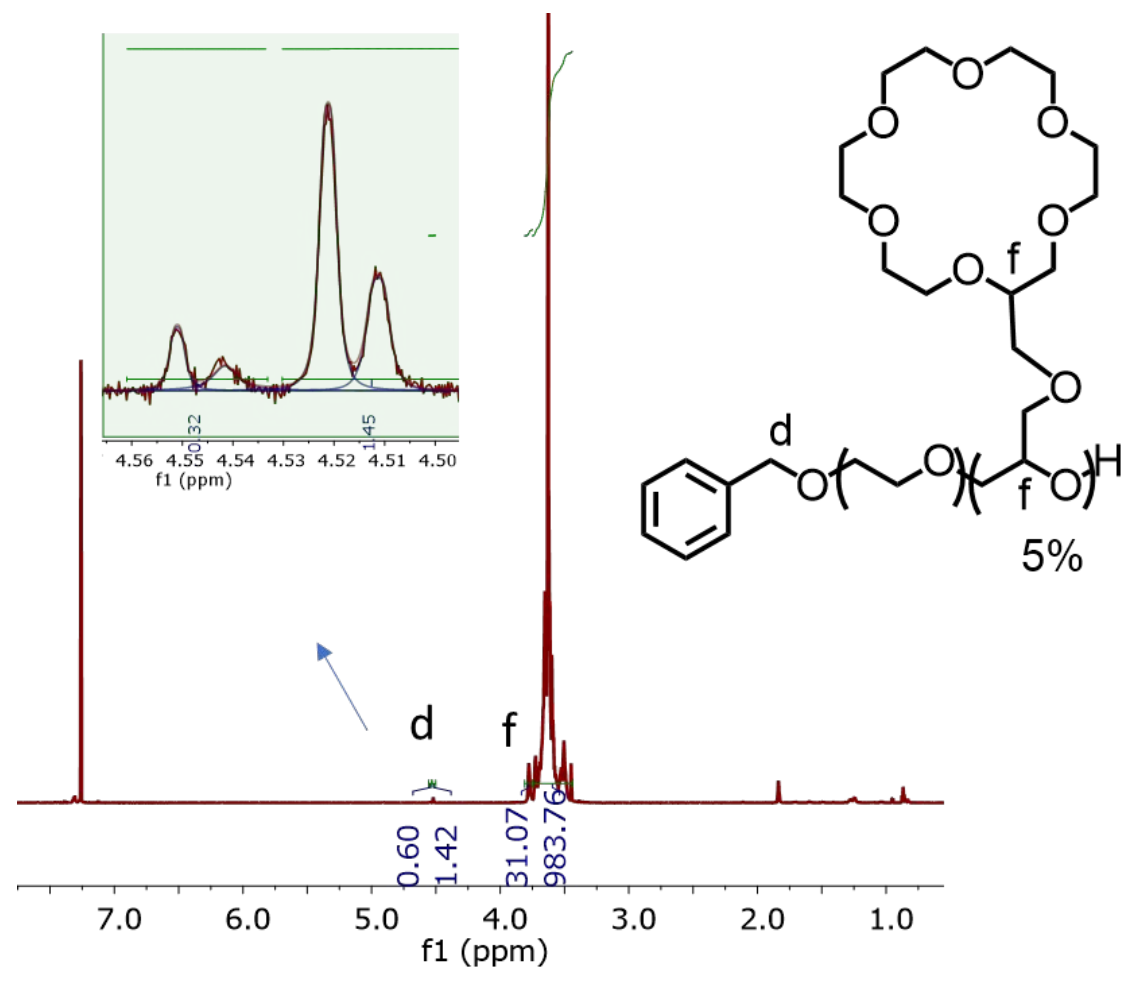

Figure S 20. ${ }^{1} \mathrm{H}$ NMR of 5\% P(EO-C6).

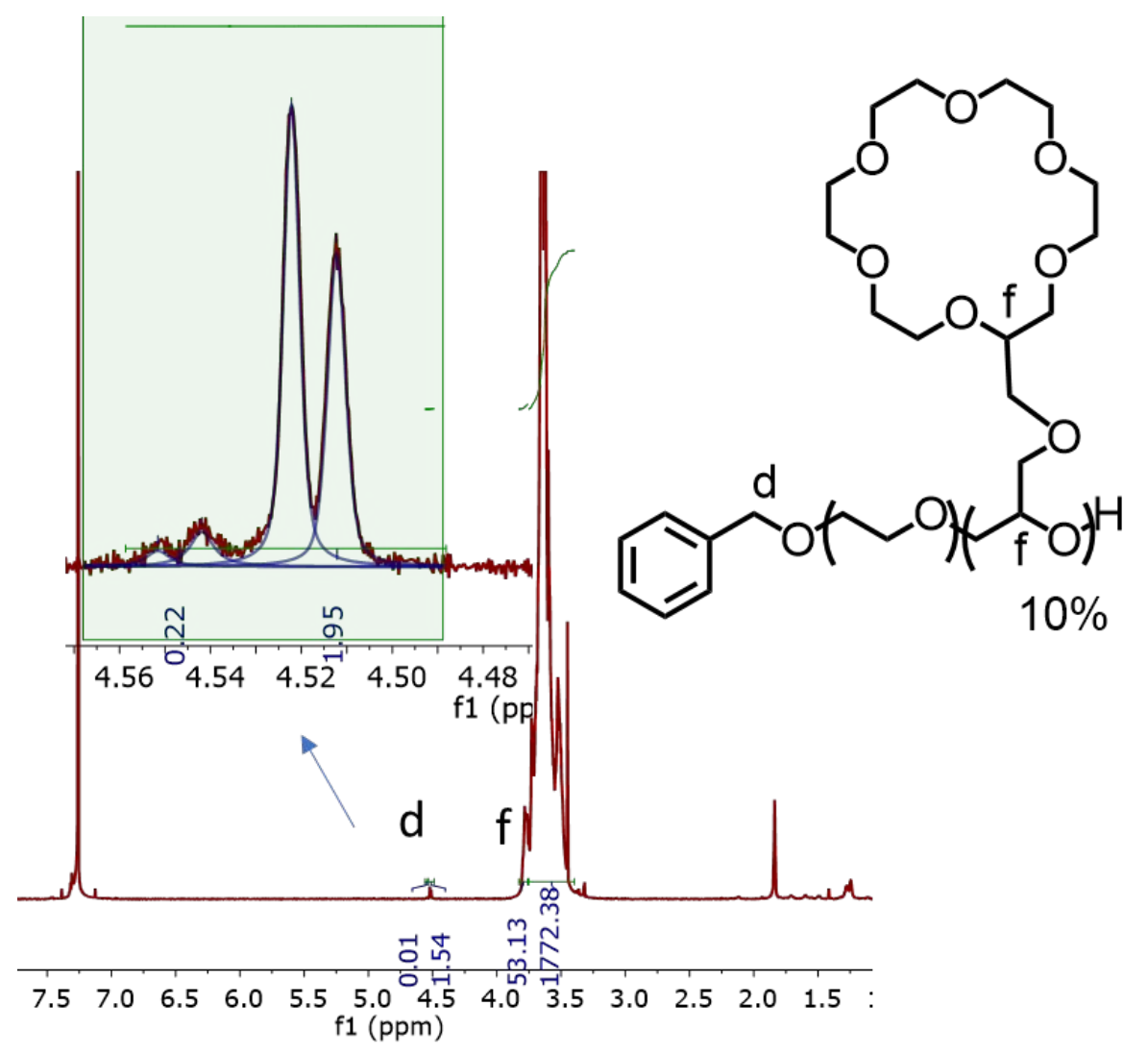

Figure S 21. ${ }^{1} \mathrm{H}$ NMR of $10 \% \mathrm{P}(\mathrm{EO}-\mathrm{C} 6)$. 
To enable the calculation of incorporation ratio of crown ether for each copolymer, higher resolution of NMR was required. As shown in Figure S22 below, proton spectrum taken on a $600 \mathrm{MHz}$ NMR spectrometer was not able to resolve signal f from major signals from backbone. However, an $800 \mathrm{MHz}$ NMR spectrometer provided baseline resolution for peak $f$.

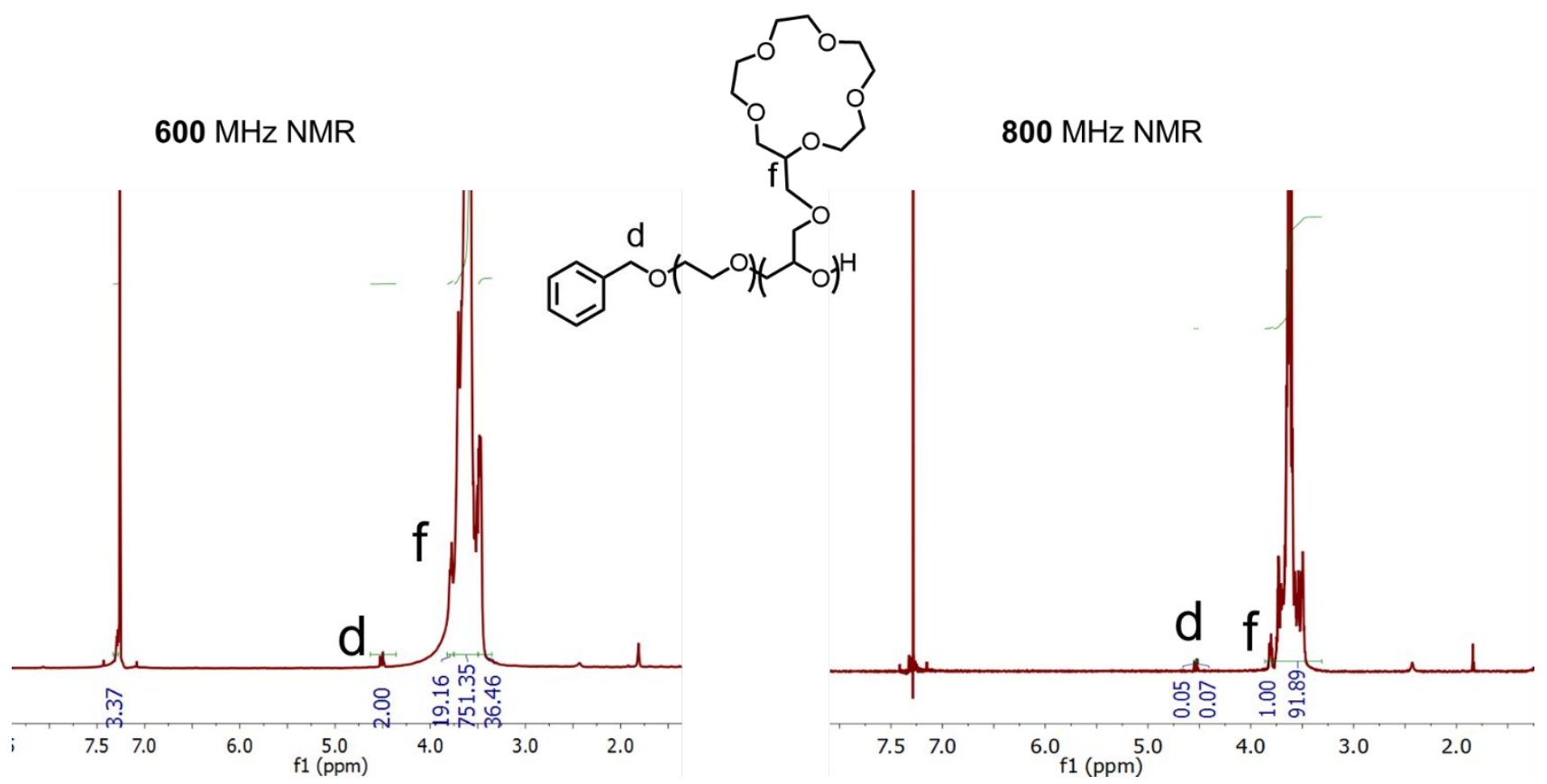

Figure S 22. Comparison between ${ }^{1} \mathrm{H}$ NMR for 5\% $\mathrm{P}(\mathrm{EO}-\mathrm{C} 5)$ performed on NMR with different resolution.

${ }^{13} \mathrm{C}$ NMR was used to further confirm incorporation ratio measured by ${ }^{1} \mathrm{H}$ NMR. First, APT experiment was carried to determine resonance from $\mathrm{C}-\mathrm{H}$ coming only from crown ether monomer. Then integral of $\mathrm{fl}$ and $\mathrm{f} 2$ were combined to be calibrated to correspond to values of two carbons from monomer. The signals below $75 \mathrm{ppm}$, assigned as all the other carbons from repeating units. After subtracting integrals of resonance from methylene carbons on crown ether comonomer (12 carbons in total), the total value left corresponds to methylene from EO. The incorporation ratio can be easily calculated from the formula listed, and was calculated to be $5 \%$, matching well with the number calculated from ${ }^{1} \mathrm{H}$ NMR for $\mathrm{P}(\mathrm{EO}-\mathrm{C} 5)$. 


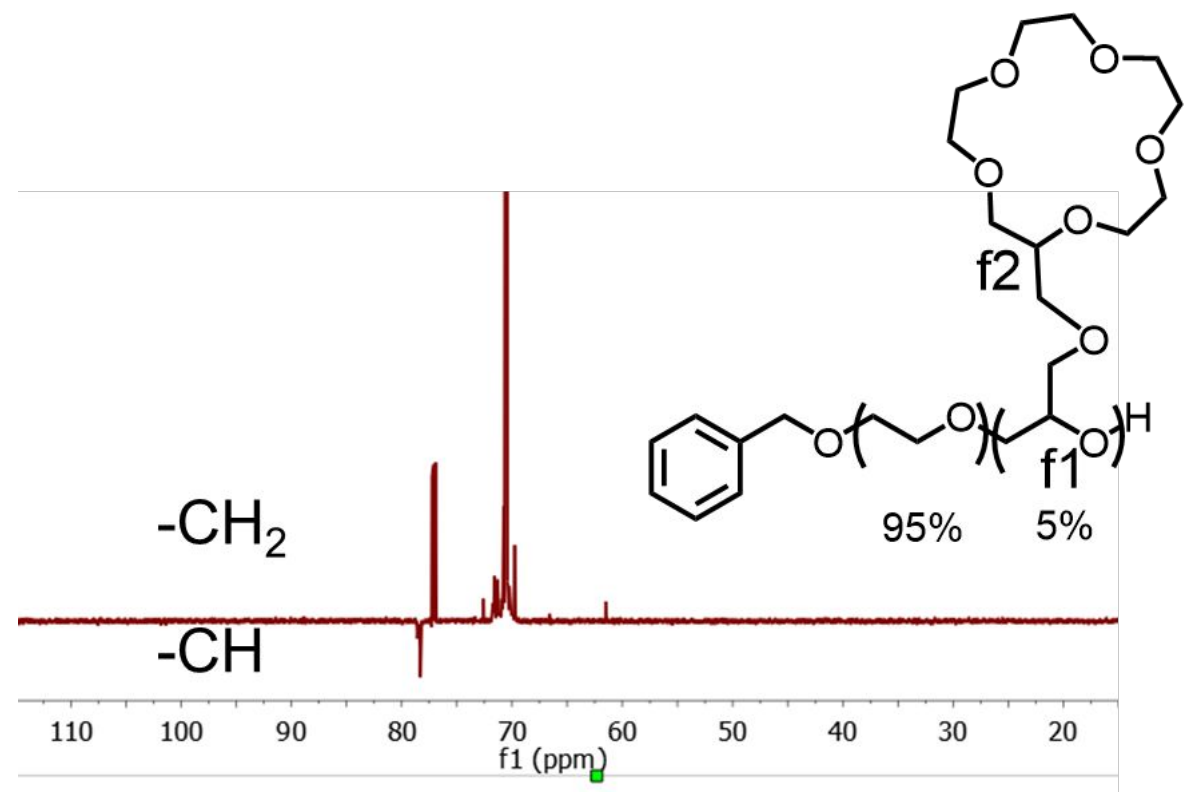

Figure S 23 . APT ${ }^{13} \mathrm{C}$ NMR for 5\% P(EO-C5) to signify methine $\mathrm{f} 1$ and $\mathrm{f} 2$.

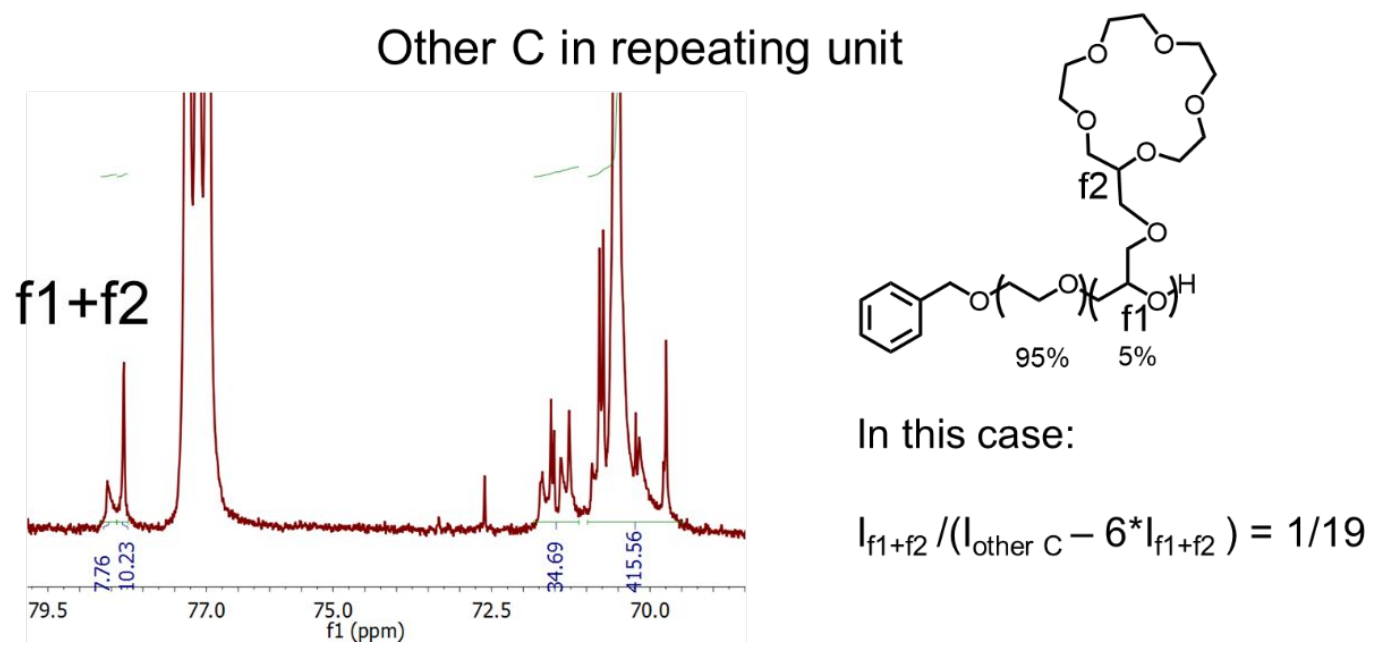

Figure S 24. Quantitative ${ }^{13} \mathrm{C}$ NMR for 5\% P(EO-C5) to confirm composition analysis. 


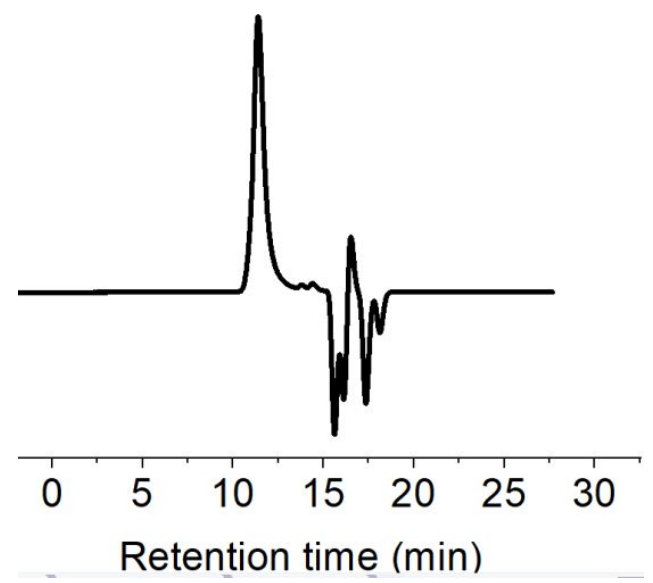

Figure S 25. Representative GPC trace of 5\% P(EO-C5) copolymer in THF versus poly(styrene) standards.

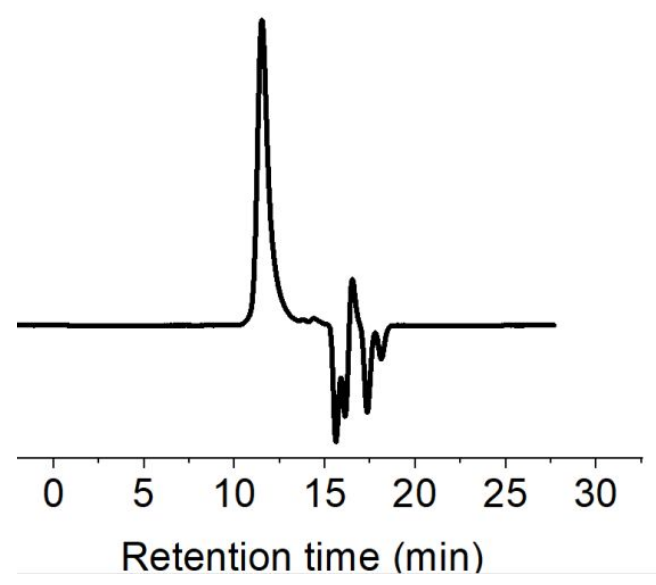

Figure S 26. Representative GPC trace of 2\% P(EO-L4) copolymer in THF versus poly(styrene) standards.

\section{Calculation of reactivity ratio.}

Figure 1 displays the initiation and first propagation step resulting in the four possible initial dimers. Assuming that the rate of initiation and first several steps of propagation is first order in monomer and initiator concentration, the change in concentration of all species is given by equation (1), where $\mathrm{k}$ is the propagation rate constant of monomer reacting with I-ER or I-EO. [I-ER-...] / [I-EO-...] could be extracted from ${ }^{1} \mathrm{H}$ NMR dyad analysis and the ratio of $[\mathrm{EO}]_{0} /[\mathrm{ER}]_{0}$ was equal to the feeding ratio. In the example shown in the next Figure for $10 \%$ P(EO-C5), [EO $]_{0} /[\mathrm{ER}]_{0}=90 / 10$. [I-ER-...] / [I-EO-...] $=1.25 / 0.70$. The ratio of propagation rate constants $\mathrm{k}_{\mathrm{ER}} / \mathrm{k}_{\mathrm{EO}}$ was easily calculated as 16 . This calculation was done for all copolymers and $\mathrm{k}_{\mathrm{ER}} / \mathrm{k}_{\mathrm{EO}}$ was averaged among all the samples. 

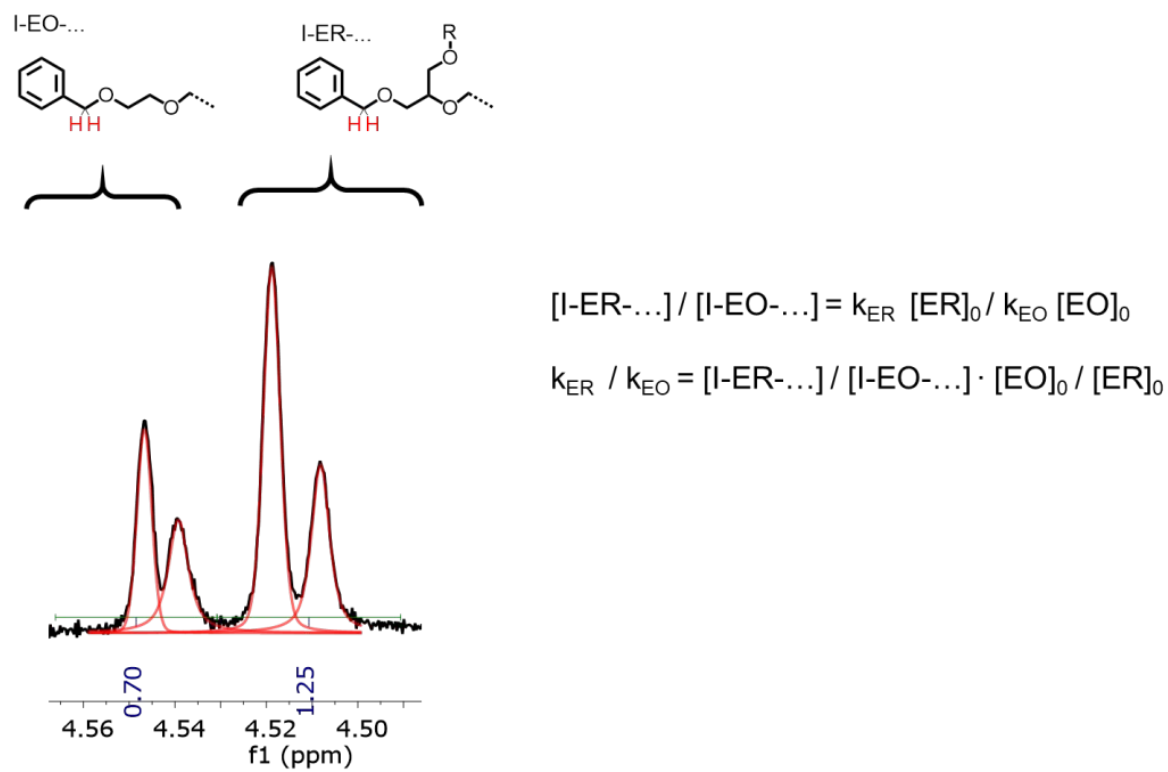

Figure S 27.Example of calculation for $\mathrm{k}_{\mathrm{ER}} / \mathrm{k}_{\mathrm{EO}}$

The reactivity ratio of the monomers toward the initiator can be determined by taking the appropriate ratio of integrals of the benzyl singlets. Carrying out the same analysis for the second monomer addition to I-EO and I-ER yields equation (3)-(6). From the ratios of the integrals for the signals due to the benzylic protons, the ratio of rate constants for ER and EO reacting with the secondary alkoxide at an ER chain end $\left(\mathrm{k}_{\mathbf{E R} / \mathbf{E R}} / \mathrm{k}_{\mathbf{E R} / \mathbf{E O}}\right)$ can be determined. The integrals of the individual benzyl singlets were evaluated by fitting four Lorentzian functions to the ${ }^{1} \mathrm{H}$ NMR data. The ratios of rate constants could then be determined for all the samples and averaged. ( $\mathrm{r}_{\mathrm{EO}}$ and $\mathrm{r}_{\mathrm{ER}}$ are 0.1 and 5.3 respectively in the example in Figure below for 10\% $\mathrm{P}(\mathrm{EO}-\mathrm{C} 5))$

However, the resultant comonomer sequence based on these reactivity ratios was gradient copolymer with significant ER enrichment at the start of the polymer chain.

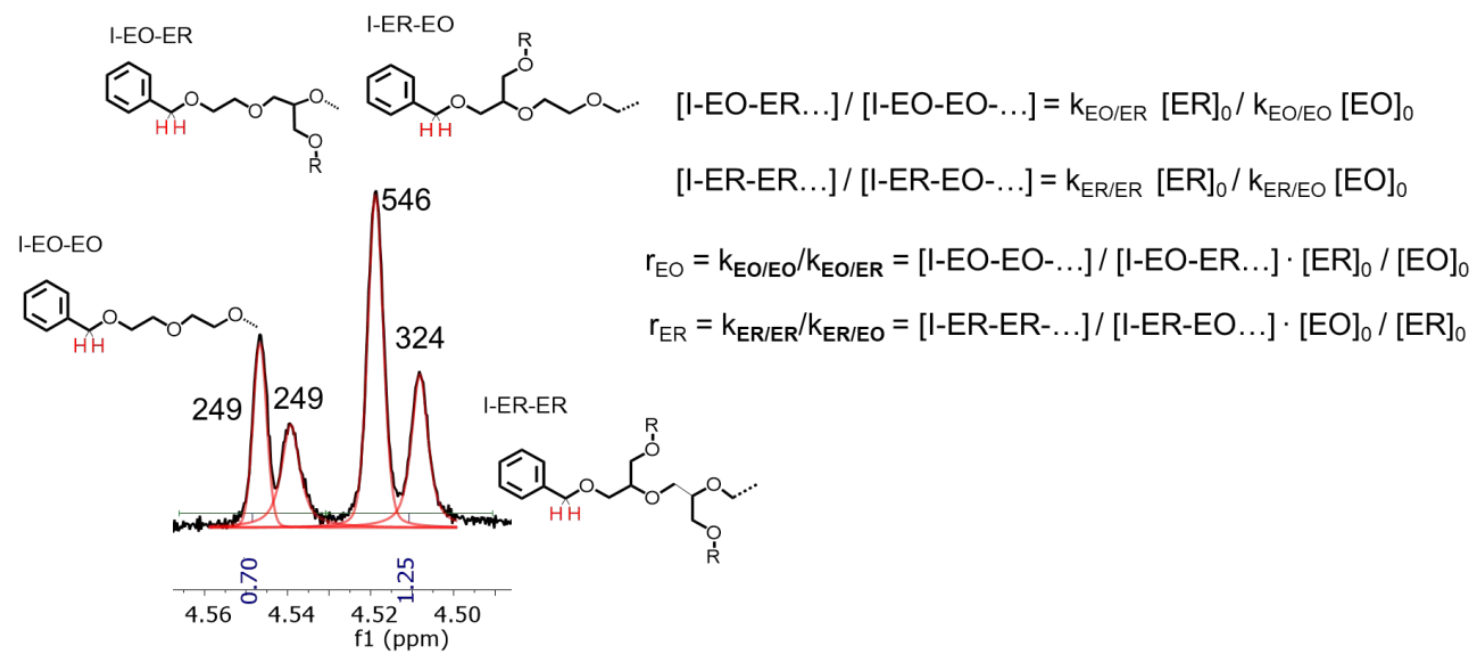

Figure $\mathrm{S}$ 28. Example of calculation for $\mathrm{r}_{\mathrm{EO}}$ and $\mathrm{r}_{\mathrm{ER}}$, numbers besides peaks indicating integrals.

Based on previous density functional calculation study, the energy of transition state was affected by coordination of the monomer to the potassium counterion and the Lewis basicity of the epoxide ring 
(electronic effect from the substituent). With side chain consisting of more ethylene oxide units, potential multidentate coordination to the potassium counterion, reactivity ratio was observed to be higher compared with EO due to lower energy barrier. In the process of initiation, potassium benzyl alkoxide was stabilized by interactions from multiple oxygens. Thus, the energy for transition state I-L4 (Figure S29 C) was expected to be lower than I-EO (Figure S29 A). When a crown ether was part of the comonomer, the size matching effect became crucial in reducing activation energy. Since it is hard for large $\mathrm{K}^{+}$to fit in 12-crown4 and ethylene oxides consisting the macrocycle had less rotation freedom, the transition state energy of IC4 (Figure S29 B) would be similar to I-EO. On the contrary, C6 had much higher initiation ratio contributed by stabilization of $\mathrm{K}^{+}$(Figure S29 D). The same rationale could be applied to explain trends in reactivity ratio of each comonomer towards EO. The comonomer to form more stable transition state with initiating/propagating species

was

A

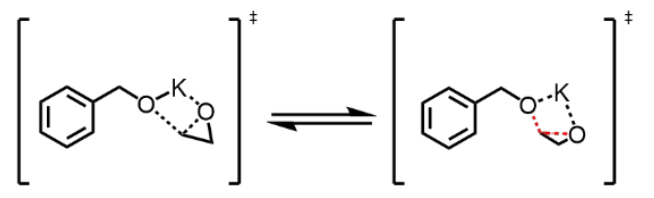

C<smiles>C=CCc1ccc(COOCOCOCOC)cc1</smiles>

B

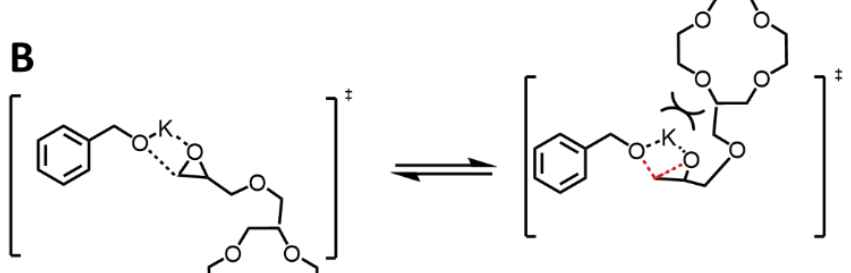

D

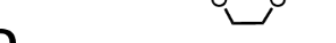

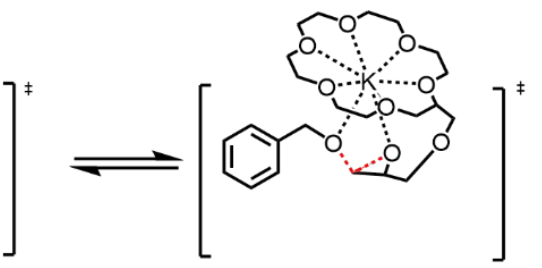

Figure S 29. Proposed transition-state structures for the first monomer additions.

\section{Comprehensive thermal characterization of copolymers.}

Table S 1. Summary of $\mathrm{T}_{\mathrm{m}}$ and enthalpy of fusion $\left(\Delta H_{f}\right)$ for all the copolymers.

\begin{tabular}{cccc}
\hline Monomer & $\mathrm{Y} \%$ & $\begin{array}{c}\Delta H_{f} \\
\mathrm{~J} / \mathrm{g}\end{array}$ & $\begin{array}{c}\mathrm{T}_{\mathrm{m}} \\
{ }^{\circ} \mathrm{C}\end{array}$ \\
\hline & 2 & 153 & 61 \\
$\mathrm{P}(\mathrm{EO}-\mathrm{L} 4)$ & 5 & 82 & 47 \\
& 10 & 27 & 10 \\
& 50 & 0 & - \\
\hline
\end{tabular}




\begin{tabular}{llll}
\hline & 2 & 95 & 48 \\
$\mathrm{P}($ EO-L5) & 5 & 62 & 38 \\
& 10 & 49 & 15 \\
& 20 & 32 & -20 \\
\hline $\mathrm{P}($ EO-L6) & 5 & 82 & 40 \\
& 10 & 32 & 19 \\
& 30 & 20 & -25 \\
\hline $\mathrm{P}($ EO-C4) & 10 & 32 & 17 \\
& 20 & 0 & - \\
\hline & 2 & 104 & 51 \\
$\mathrm{P}($ EO-C5 $)$ & 5 & 56 & 38 \\
& 10 & 48 & 33 \\
& 20 & 0 & - \\
\hline $\mathrm{P}($ EO-C6) & 5 & 62 & 44 \\
& 10 & 24 & 10 \\
\hline & & & 55 \\
\hline
\end{tabular}

When the same DSC sample of $10 \% \mathrm{P}(\mathrm{EO}-\mathrm{L} 5)$ was measured at various scan rates, there were variations in the DSC data. Scanning at 5 times slower rate $\left(2^{\circ} \mathrm{C} / \mathrm{min}\right)$, cold crystallization was no longer observed. Because of the fast scan rate and small temperature difference between the $T_{m}$ and $T_{g}$, there was not enough time given for crystalline domains to order before getting trapped in a glassy material. However, the value of melting point was not affected, and thus all $\mathrm{T}_{\mathrm{m}}$ reported in this paper was measured at a standard $10^{\circ} \mathrm{C} / \mathrm{min}$. 


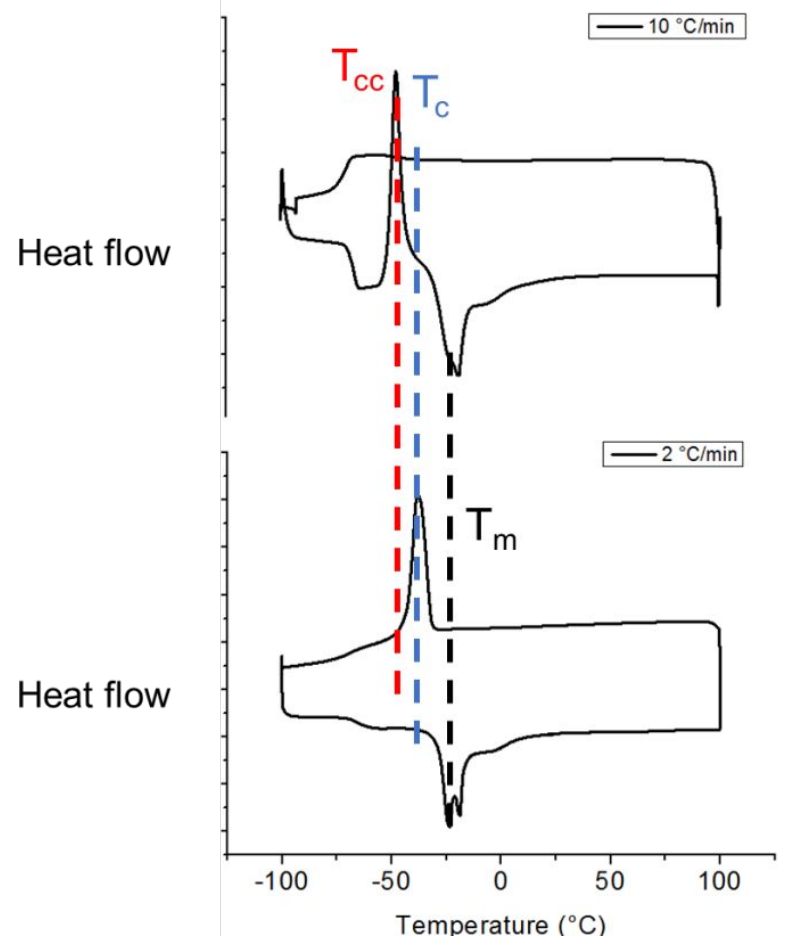

Figure S 30. DSC curve for $10 \% \mathrm{P}(\mathrm{EO}-\mathrm{L} 5)$ at scan rates of $10^{\circ} \mathrm{C} / \mathrm{min}$ (top) and $2{ }^{\circ} \mathrm{C} / \mathrm{min}$ (bottom).

\section{Cloud point of copolymers.}

UV absorbance of solution is used to measure cloud point of polymers. All polymers are completely dissolved in aqueous solution with transmission above $90 \%$ in a closed quartz cuvette. As temperature rises by $5^{\circ} \mathrm{C} / \mathrm{min}$, the solution gradually turns cloudy. When transmission dropped to $50 \%$, the corresponding temperature was recorded as the cloud point. For example, the cloud point for $10 \% \mathrm{P}(\mathrm{EO}-\mathrm{L} 4)$ was $86^{\circ} \mathrm{C}$, as shown in the Figure 31 below.

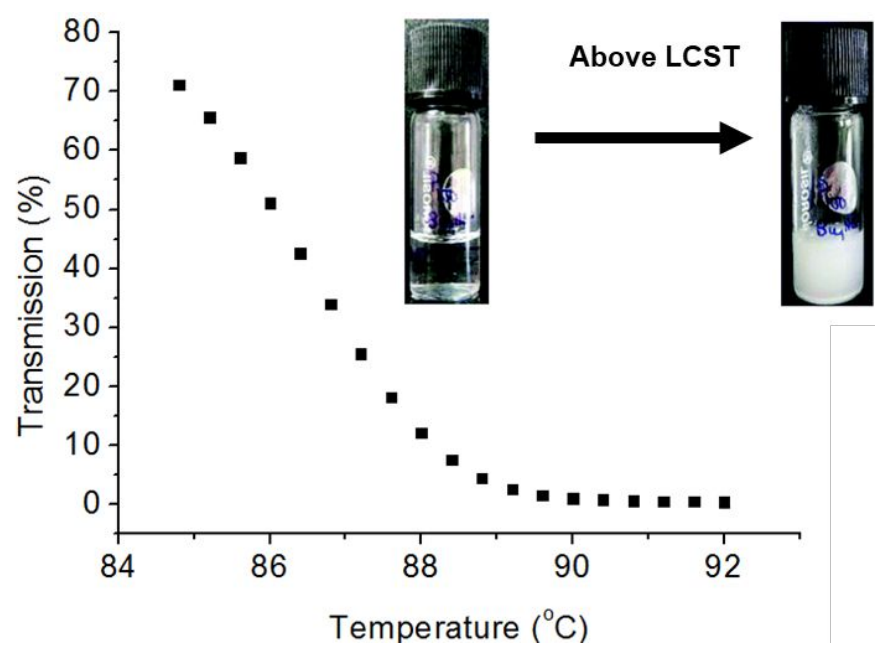

Figure S 31. Temperature dependent transmittance curve for $10 \% \mathrm{P}(\mathrm{EO}-\mathrm{L} 4)$ at $5 \mathrm{mg} / \mathrm{ml}(0.5 \mathrm{mM})$ in $0.5 \mathrm{M} \mathrm{NaCl}$ solution. 
With more oxirane with linear side chain incorporated (L4 in Table S 2) into the polymer chain, the cloud point continued to drop, indicating these ethylene oxide side chains contribute to disrupting hydrogen bonding of the main chain with water.

Table S 3. Summary of cloud point for EO-L4 copolymer series measured in DI water at $10 \mathrm{mg} / \mathrm{ml}$.

\begin{tabular}{|l|l|l|}
\hline $\mathrm{Y} \%$ & $\begin{array}{l}\mathrm{M}_{\mathrm{n}} \\
\mathrm{kDa}\end{array}$ & $\begin{array}{l}\text { cloud point } \\
{ }^{\circ} \mathrm{C}\end{array}$ \\
\hline 50 & 17 & 64 \\
\hline 10 & 15 & 75 \\
\hline 2 & 20 & 88 \\
\hline 0 & 16 & $>100$ \\
\hline
\end{tabular}

With the number of ethylene oxide units increasing in linear side chains, the cloud point slightly increased. Interestingly, the cloud point is not sensitive to species of cation in salt solution.

Table S 4. cloud point for copolymers with linear side chains measured in salt solutions $(0.5 \mathrm{M})$ at $5 \mathrm{mg} / \mathrm{ml}$. Incorporation of comonomers was $10 \mathrm{~mol} \%$ for all copolymers.

\begin{tabular}{|l|l|l|}
\hline Copolymer & Salt & $\begin{array}{l}\text { cloud point } \\
{ }^{\circ} \mathrm{C}\end{array}$ \\
\hline $\mathrm{P}($ EO-L4) & $\mathrm{CsCl}$ & 85 \\
\hline $\mathrm{P}($ EO-L4) & $\mathrm{NaCl}$ & 86 \\
\hline $\mathrm{P}($ EO-L5) & $\mathrm{NaCl}$ & 93 \\
\hline $\mathrm{P}($ EO-L6) & $\mathrm{NaCl}$ & 94 \\
\hline $\mathrm{P}($ EO-DL7) & $\mathrm{NaCl}$ & 97 \\
\hline
\end{tabular}

\section{PEO-based copolymers with dispersed PEG side chain.}

Table S 5. Characterization of copolymers from ethylene oxide and dispersed monomer DL7.

\begin{tabular}{llll}
\hline Polymer & $\begin{array}{l}M_{\mathrm{n}}(\mathrm{NMR}) \\
\mathrm{kDa}\end{array}$ & $\begin{array}{l}M_{\mathrm{n}}(\mathrm{GPC}) \\
\mathrm{kDa}\end{array}$ & $Ð$ \\
\hline $\mathrm{P}($ EO-DL7) & 15 & 17 & 1.09 \\
$\mathrm{P}(\text { EO-DL7 })_{15}$ & 9 & 8 & 1.17
\end{tabular}


The $\mathrm{T}_{\mathrm{m}}$ of $5 \% \mathrm{P}(\mathrm{EO}-\mathrm{DL} 7)$ with disperse side chains is slightly lower than the $\mathrm{T}_{\mathrm{m}}$ of $\mathrm{P}(\mathrm{EO}-\mathrm{L} 6)$ constructed from a monomer with discrete side chains, while the copolymer still demonstrated significantly lowered crystallinity compared to the PEO homopolymer.

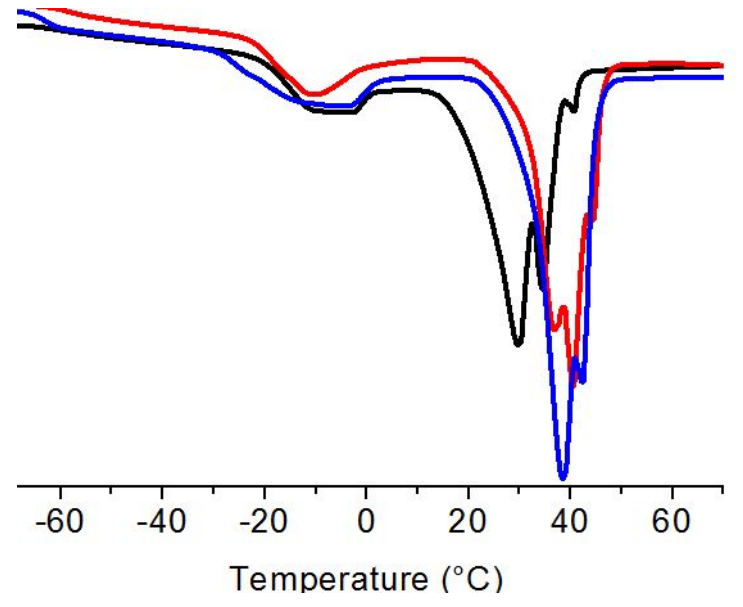

Figure S 32. Comparison of DSC curve for 5\% P(EO-DL7) (black), 5\% P(EO-L5) (blue) and 5\% $\mathrm{P}(\mathrm{EO}-\mathrm{L} 6)$ (red).

\section{Conductivity characterization of PEO-based copolymers.}

Preparation of metal salt-containing polymers. Polymers were dried in a vacuum oven at $60{ }^{\circ} \mathrm{C}$ in the presence of $\mathrm{P}_{2} \mathrm{O}_{5}$ for two days before transferring to a nitrogen glove box. The polymers were then dissolved in anhydrous methanol, and $1.5 \mathrm{M}$ stock solutions of $\mathrm{Li}^{+}$(Alfa Aesar) and $\mathrm{Na}^{+}$ (Solvionic) bis(trifluoromethylsulfonyl)imide (TFSI ${ }^{-}$) salts in anhydrous methanol were added to the polymer in appropriate amounts to reach nominal metal cation-to-crown or -branch ether molar ratios of 0.25 . The sample vials were sealed, frozen in liquid nitrogen outside of the glove box, and dried in vacuo $\left(1 \times 10^{-3}\right.$ Torr) first at room temperature overnight, then at $60{ }^{\circ} \mathrm{C}$ for $24 \mathrm{~h}$. The samples were then transferred to a high vacuum oven $\left(4 \times 10^{-8}\right.$ Torr $)$ for 4 days at $60{ }^{\circ} \mathrm{C}$ to ensure complete removal of solvent. The dried samples were transferred into a nitrogen glove box for storage and measurement.

Thermal characterization. Hermetic aluminum DSC pans were loaded with polymer samples in a nitrogen glove box. The sample pans were sealed quickly outside of the glove box. Three heating and cooling scans were performed from $-150{ }^{\circ} \mathrm{C}$ to $120^{\circ} \mathrm{C}$ at $20^{\circ} \mathrm{C} \mathrm{min}{ }^{-1}$ on a TA Instruments Q2000 DSC. The glass transition temperature $\left(T_{\mathrm{g}}\right)$ of each sample was measured on second heating using the midpoint method. 


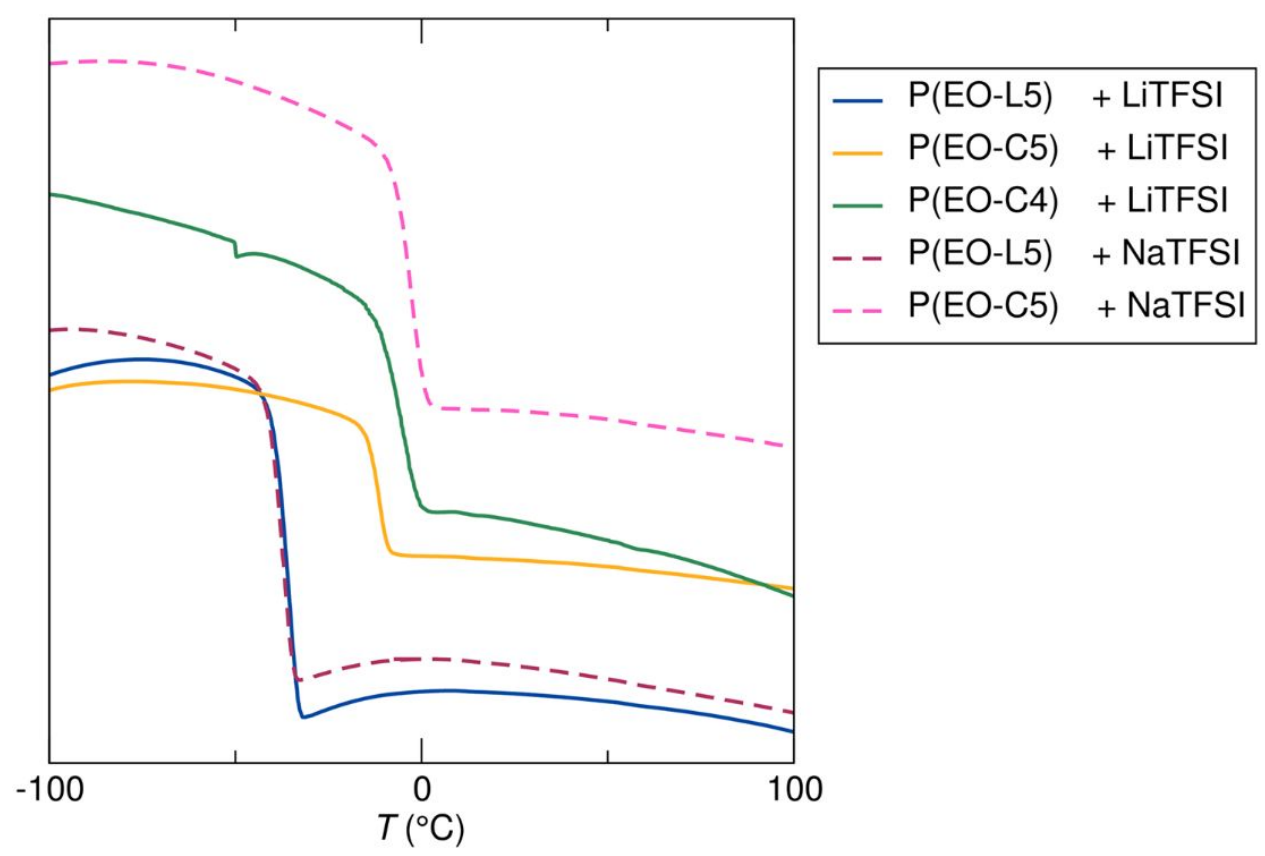

Figuer S 33. DSC thermograms for polymer-salt blend. Each copolymer was doped with 0.25 equivalent LiTFSI or NaTFSI per branch, corresponding to $13 \mathrm{wt} \%$ of salts in polymer-salt blends. Incorporation of comonomers was $20 \mathrm{~mol} \%$ for all copolymers.

Ionic conductivity characterization. Total ionic conductivity was measured as a function of temperature on samples sandwiched between parallel ITO blocking electrodes using electrochemical impedance spectroscopy (EIS). The ITO-coated glass electrodes were cleaned by sonication for 5 min each in detergent, DI water, acetone and isopropyl alcohol, followed by a 5 min UV/ozone treatment. The electrode thicknesses were measured using a micrometer, after which a double-sided Kapton tape spacer with a $1 / 8$ " hole was added to one electrode. Polymer samples were loaded into the hole in the Kapton spacer in a nitrogen glove box. Samples were heated to about $30^{\circ} \mathrm{C}$ above their $T_{\mathrm{g}}$ before being sealed with a second ITO electrode. All samples were then heated to $90{ }^{\circ} \mathrm{C}$ and pressed in a hand press. The final stack thickness was measured using a micrometer, and the sample thickness was determined by subtracting the electrode thicknesses. EIS was measured with a Biologic SP-200 potentiostat using a sinusoidal $100 \mathrm{mV}$ signal from $1 \mathrm{MHz}$ to $1 \mathrm{~Hz}$ at temperatures ranging from $30^{\circ} \mathrm{C}$ to $110^{\circ} \mathrm{C}$. The data was converted into dielectric storage and loss, and the ionic conductivities determined from the real component of conductivity at the maximum in $\tan (\delta) .{ }^{1}$ Two samples were measured for each composition. 


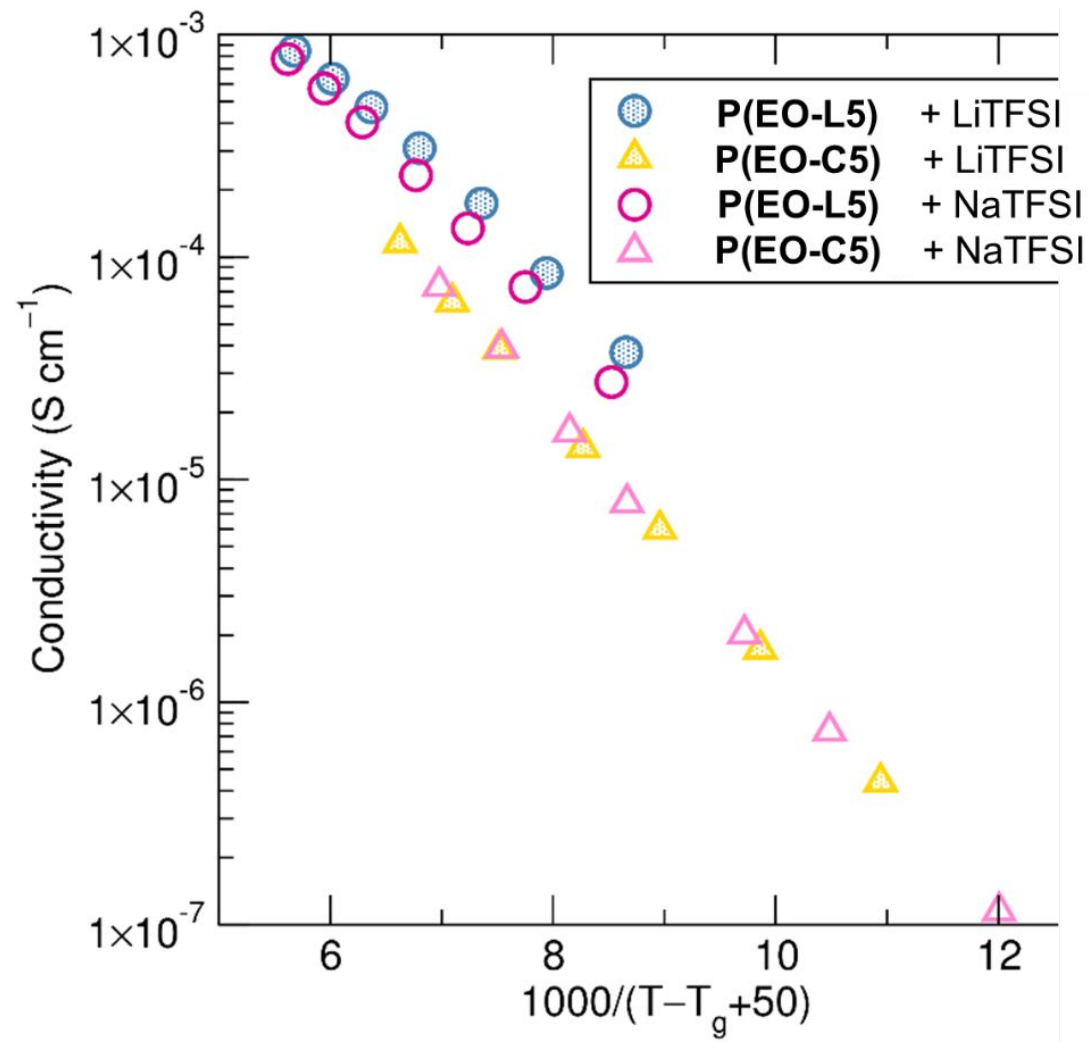

Figure $\mathrm{S} 34$. $\mathrm{T}_{\mathrm{g}}$-normalized ionic conductivity collapses the conductivity differences between the Li-doped and Na-doped series, but continues to show improved performance of the linear copolymer, P(EO-L5), over the crown-ether analogue, P(EO-C5). Each copolymer was doped with 0.25 equivalent LiTFSI or NaTFSI per branch, corresponding to $13 \mathrm{wt} \%$ of salts in polymersalt blends. Incorporation of comonomers was $20 \mathrm{~mol} \%$ for all copolymers. 